\title{
Pulmonary hypertension in chronic obstructive pulmonary disease
}

\author{
J.A. Barberà, V.I. Peinado, S. Santos
}

Pulmonary hypertension in chronic obstructive pulmonary disease. J.A. Barberà, V.I. Peinado, S. Santos. C) ERS Journals Ltd 2003.

ABSTRACT: Pulmonary hypertension is a common complication of chronic obstructive pulmonary disease (COPD). Its presence is associated with shorter survival and worse clinical evolution. In COPD, pulmonary hypertension tends to be of moderate severity and progresses slowly. However, transitory increases of pulmonary artery pressure may occur during exacerbations, exercise and sleep. Right ventricular function is only mildly impaired with preservation of the cardiac output.

Structural and functional changes of pulmonary circulation are apparent at the initial stages of COPD. Recent investigations have shown endothelial dysfunction and changes in the expression of endothelium-derived mediators that regulate vascular tone and cell growth in the pulmonary arteries of patients with mild disease. Some of these changes are also present in smokers with normal lung function. Accordingly, it has been postulated that the initial event in the natural history of pulmonary hypertension in COPD could be the lesion of pulmonary endothelium by cigarettesmoke products.

Long-term oxygen administration is the only treatment that slows down the progression of pulmonary hypertension in chronic obstructive pulmonary disease. Nevertheless, with this treatment pulmonary artery pressure rarely returns to normal values and the structural abnormalities of pulmonary vessels remain unaltered. Vasodilators are not recommended on the basis of their minimal clinical efficacy and because they impair pulmonary gas exchange. Recognition of the role of endothelial dysfunction in the physiopathology of pulmonary hypertension in chronic obstructive pulmonary disease opens new perspectives for the treatment of this complication.

Eur Respir J 2003; 21: 892-905.
Dept of Pulmonary Medicine, Institute of Biomedical Research Augusti Pi i Sunyer (IDIBAPS), Hospital Clinic, University of Barcelona, Spain.

Correspondence: J.A. Barberà, Servei de Pneumologia, Hospital Clínic, Villarroel, 170. 08036 Barcelona, Spain

Fax: 34932275455

E-mail: jbarbera@clinic.ub.es.

Keywords: Chronic hypoxaemia

cigarette-smoke effects

endothelium

pulmonary artery

vascular remodelling

vasodilators

Received: December 122002

Accepted after revision: January 162003

The authors have been supported, in part, by research grants from Fondo de Investigación Sanitaria (FIS), Sociedad Española de Neumología y Cirugía Torácica (SEPAR), and Societat Catalana de Pneumologia (SOCAP).
Pulmonary hypertension is a frequent complication in the natural history of chronic obstructive pulmonary disease (COPD). Its presence is associated with shorter survival rates and it has been identified as a predictive factor of worse clinical outcomes and frequent use of health resources. At the present time, there is no specific and effective treatment for this condition in COPD. However, recent advances in knowledge of the pathogenesis of pulmonary hypertensive states, along with the development of new and effective strategies in the treatment of pulmonary hypertension, open a new perspective that could be applicable in COPD. Therefore, it is appropriate to revisit this old topic $[1,2]$ in the light of new discoveries in this field. In this report the different aspects of pulmonary hypertension associated with COPD are reviewed with special emphasis placed on the recent advances in the knowledge of the pathogenesis of COPD and the potential implications of these findings in treatment perspectives.

\section{Incidence}

The actual incidence of pulmonary hypertension in COPD is not known, because it has not been screened systematically using reliable diagnostic tools (right heart catheterisation) in the wide clinical spectrum of COPD. However, indirect data suggests that the incidence of pulmonary hypertension in COPD is high.

Anatomical evidence of right-ventricular hypertrophy can be found at autopsy in up to $40 \%$ of patients with COPD [1, 3]. However, there are discrepancies between different series because of the lack of a unified morphological criteria used to define right-ventricular hypertrophy [3].

Direct measurements of pulmonary artery pressure $(P \mathrm{pa})$ obtained at right-heart catheterisation have been conducted only in small series of patients. In 1972 BuRRows et al. [4] reported the haemodynamic findings in a group of 50 patients with severe COPD (ratio: forced expiratory volume in one

Previous articles in this series: No. 1: Humbert M, Trembath RC. Genetics of pulmonary hypertension: from bench to bedside. Eur Respir J 2002; 20 741-749. No. 2: Galiè N, Manes A, Branzi A. The new clinical trials on pharmacological treatment in pulmonary arterial hypertension. Eur Respir $J$ 2002; 20: 1037-1049. No. 3: Chemla D, Castelain V, Hervé P, Lecarpentier Y, Brimioulle S. Haemodynamic evaluation of pulmonary hypertension. Eur Respir J 2002; 20: 1314-1331. No. 4: Eddahibi S, Morrell N, d'Ortho M-P, Naeije R, Adnot S. Pathobiology of pulmonary arterial hypertension. Eur Respir J 2002; 20: 1559-1572. No. 5: Widlitz A, Barst RJ. Pulmonary arterial hypertension in children. Eur Respir J 2003; 21: 155-176. No. 6: Moloney ED, Evans TW. Pathophysiology and pharmacological treatment of pulmonary hypertension in acute respiratory distress syndrome. Eur Respir J 2003; 21: 720-727. 
second (FEV1)/vital capacity (VC), 37\%). The average value of mean $P$ pa was $3.46 \mathrm{kPa}(26 \mathrm{mmHg})$, with $20 \%$ of the patients showing $P$ pa above this average value [4]. In a series of 175 patients with severe COPD (ratio: FEV1/VC, 40\%) and mild hypoxaemia (arterial oxygen tension $\left(\mathrm{Pa}, \mathrm{O}_{2}\right) 8.38 \mathrm{kPa}$ $(63 \mathrm{mmHg}))$, reported by WeITZENBLUM et al. [5], the number of patients with pulmonary hypertension (mean $P$ pa $>2.66 \mathrm{kPa}$ $(20 \mathrm{mmHg}))$ was $62(35 \%$ of the whole group). The same group of investigators reported a similar incidence of pulmonary hypertension in a subsequent study carried out in 93 patients, 32 of them (34\%) had a mean $P$ pa $>2.66 \mathrm{kPa}(20 \mathrm{mmHg})[6]$.

Contrasting with these figures, in a recent study performed in 120 patients with severe emphysema (FEV1: 27\% predicted; $\left.P \mathrm{a}, \mathrm{O}_{2}: 8.78 \mathrm{kPa}(66 \mathrm{mmHg})\right)$, SCHARF et al. [7] reported a very high incidence of pulmonary hypertension; $91 \%$ of the patients had mean $P$ pa values $>2.66 \mathrm{kPa}(20 \mathrm{mmHg})$. It is of note that in this series pulmonary capillary wedge pressure $(P$ pcw $)$ was also high, $61 \%$ of the patients had $P$ pcw $>1.6 \mathrm{kPa}$ $(12 \mathrm{mmHg})$ [7]. Despite the fact that hyperinflation could be a potential explanation for the high incidence of pulmonary hypertension in this group of patients, the findings by SHARF et al. [7] challenge the classical notion that COPD patients with an emphysematous phenotype usually do not show pulmonary hypertension [4].

\section{Clinical relevance}

In COPD, the presence of pulmonary hypertension is associated with shorter survival rates. In a longitudinal 7-yr study of 50 patients with COPD, BuRrows et al. [4] showed that their survival was inversely related to pulmonary vascular resistance (PVR) and that the correlation of survival with PVR was similar to that shown with FEV1. In a 15-yr follow-up study conducted in 200 patients with COPD, TRAVER et al. [8] showed that, after correcting for age, the presence or absence of cor pulmonale was one of the best predictors of mortality. In 1981, WeITZENBLUM et al. [5] showed in 175 patients with COPD that those with $P$ pa $>2.66 \mathrm{kPa}(20 \mathrm{mmHg})$ had a shorter survival than those whose $P$ pa was normal.

It should be noted that these studies were conducted before long-term oxygen therapy (LTOT) was introduced as a regular treatment of chronic respiratory failure in COPD. In a more recent study by OsWALD-MAMMOSER et al. [9], performed in 84 patients receiving LTOT, these authors showed that $P$ pa was the single best predictor of mortality. The 5-yr survival rate was $36 \%$ in patients with $P$ pa $>3.33 \mathrm{kPa}$ $(25 \mathrm{mmHg})$, whereas in patients with $P$ pa $<3.33 \mathrm{kPa}(25 \mathrm{mmHg})$ the survival rate was $62 \%$ [9]. Interestingly, in this study neither the FEV1 nor the degree of hypoxaemia or hypercapnia had prognostic value [9].

The relevance of pulmonary hypertension and right-ventricular dysfunction as prognostic determinants in COPD is further emphasised by the recent findings reported by BURGESS et al. [10] who showed that echocardiographic indices of rightventricular function were predictive of survival in a group of 87 COPD patients. Furthermore, InCALZI et al. [11] have shown that electrocardiographical signs of right-ventricular hypertrophy or right-atrial overload were also predictive for survival in COPD.

In addition to the prognostic significance in relation to survival, the presence of pulmonary hypertension in COPD is also associated with a poorer clinical evolution and more frequent use of healthcare resources [12]. In a group of 64 patients admitted to the hospital because of an acute exacerbation, KESSLER et al. [12] showed that the presence of a mean $P$ pa $>2.4 \mathrm{kPa}(18 \mathrm{mmHg})$ was one of the best predictors of an increased risk of hospitalisation for acute exacerbation in the subsequent months. Interestingly, in this series, parameters commonly used to assess disease severity, namely FEV1 or $\mathrm{Pa}, \mathrm{O}_{2}$, were not related to the risk of hospitalisation [12]. These findings suggest that patients with an abnormal pulmonary vascular bed might have fewer functional reserves to overcome the potential complications that occur during the evolution of the disease, hence needing hospital admissions more frequently.

\section{Natural history of pulmonary hypertension in chronic obstructive pulmonary disease}

Pulmonary hypertension in COPD progresses over time and its severity correlates with the degree of airflow obstruction and the impairment of pulmonary gas exchange $[6,7]$. However, the rate of progression of pulmonary hypertension in COPD is slow and usually $P$ pa is only moderately elevated, even in patients with advanced disease [7]. WEITZENBLUM et al. [6] studied the evolution of $P$ pa in a group of 93 patients with COPD for $\sim 5$ yrs. They found that $P$ pa increased at an average rate of $0.08 \mathrm{kPa}(0.6 \mathrm{mmHg})$ per yr [6]. The rate of increase of $P$ pa was slightly higher in patients who did not have pulmonary hypertension at the beginning of the study, as compared with those who already had pulmonary hypertension [6]. Nevertheless, the evolution of $P$ pa was more closely linked to the evolution of arterial blood gases than to the initial $P$ pa value [6].

An intriguing question is when pulmonary hypertension commences in the natural history of COPD. In a recent study, KESSLER et al. [13] assessed the evolution of pulmonary haemodynamics in a group of 131 patients with moderate COPD (FEV1, 45\% pred) who did not have pulmonary hypertension at rest, although 76 patients (58\%) developed pulmonary hypertension during exercise. In a second catheterisation, performed 7-yrs later, $P$ pa had increased by $0.35 \mathrm{kPa}$ $(2.6 \mathrm{mmHg})$, with an annual rise of $0.05 \mathrm{kPa}(0.4 \mathrm{mmHg})$ per yr. In this second study, 33 patients from the entire group $(25 \%)$ had pulmonary hypertension at rest. Interestingly, the incidence of pulmonary hypertension in the group of patients who at the initial catheterisation developed pulmonary hypertension during exercise $(32 \%)$ was significantly higher than in those without exercise-induced pulmonary hypertension $(16 \%)$. A logistic regression analysis showed that the $P$ pa value during exercise was an independent predictor for the subsequent development of pulmonary hypertension [13]. These results indicate that in COPD, changes in pulmonary circulation may start several years before pulmonary hypertension is apparent at rest and that exercise testing might be useful in showing abnormalities of the pulmonary circulation. These observations are consistent with the results of morphometric studies showing conspicuous changes in the structure of pulmonary muscular arteries in patients with mild COPD [14, 15].

\section{New concepts in pathogenesis}

A variety of factors may contribute to the development and maintenance of pulmonary hypertension in COPD. The most significant of which are the remodelling of pulmonary vessels and hypoxic pulmonary vasoconstriction. Understanding of the etiopathogenic mechanisms responsible for pulmonary vascular abnormalities in COPD remain incomplete, however, they have been extensively investigated in recent years. 


\section{Characteristics of pulmonary vascular remodelling}

Patients with end-stage COPD and cor pulmonale show striking changes in pulmonary muscular arteries and precapillary vessels that explain the irreversible increase of pulmonary vascular resistance [16]. Post-mortem studies in these patients have revealed deposition of longitudinal muscle and fibrosis of the intima in pulmonary muscular arteries and the development of a medial coat of circular smooth muscle, bounded by a new elastic lamina, in arterioles [16, 17]. However, remodelling of pulmonary arteries is not exclusive to patients with advanced disease as it has also been shown in patients with mild COPD [14, 15, 18-20]. Pulmonary vascular abnormalities in patients with mild-to-moderate disease mainly consist of thickening of the intima of pulmonary muscular arteries which reduces the lumen size and an increased proportion of muscularised arterioles [14, 15, 18-20]. Changes in the muscular layer are less conspicuous and the majority of studies have failed to show muscular hypertrophy. Histochemical and immunohistochemical studies conducted in pulmonary muscular arteries of patients with mild COPD indicate that the enlargement of the intima is produced by the proliferation of smooth-muscle cells (fig. 1a), some of which have lost the contractile phenotype, and the deposition of

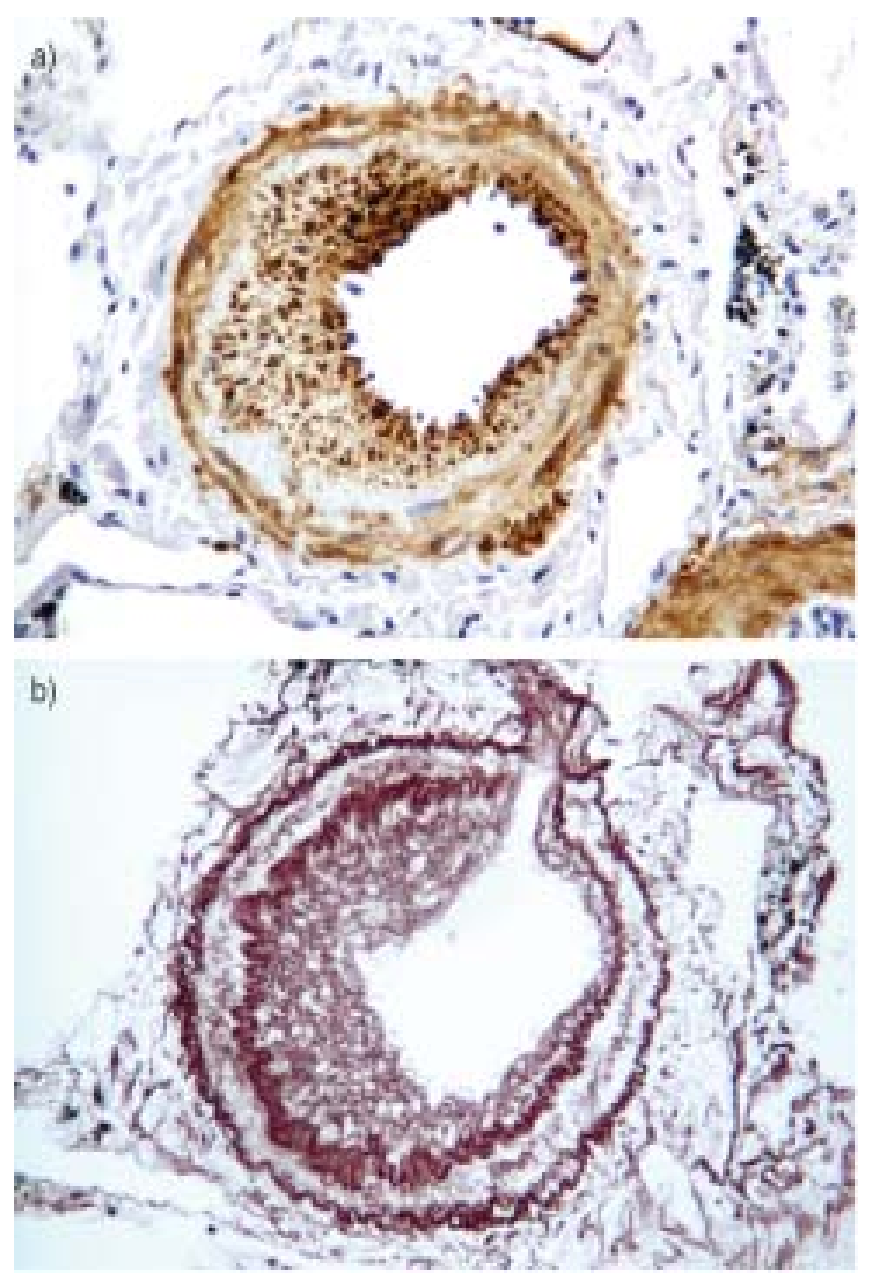

Fig. 1.-Pulmonary muscular artery from a patient with chronic obstructive pulmonary disease. Note the prominent intimal thickening and the luminal narrowing. a) Immunostaining with monoclonal antibody against $\alpha$-smooth muscle actin, showing abundant proliferation of smooth-muscle cells in the intima. b) Orcein stain disclosing abundant deposition of elastic fibres in the intimal layer. Internal scale bar $=42.2 \mu \mathrm{m}$. both elastic and collagen fibres (fig. 1b). The nature of cell proliferation and extracellular matrix protein deposition in patients with mild disease closely resembles that shown in patients with end-stage COPD [17, 21]. Interestingly, studies conducted in smokers with normal lung function have also revealed intimal thickening in pulmonary muscular arteries [15], the characteristics of which do not differ from that shown in patients with mild COPD [21].

\section{Endothelial dysfunction}

Vascular actions of endothelium are mediated through the balanced release of potent vasoactive mediators, such as nitric oxide (NO), prostacyclin, endothelin (ET)-1 and angiotensin, under both physiological and pathological conditions. Some of these mediators also have antiproliferative and anti-inflammatory properties. For these reasons, endothelial function plays a pivotal role in preserving the integrity of the vessel wall.

Endothelial dysfunction in pulmonary arteries has been shown at both ends of the COPD spectrum, end-stage disease [22] and early mild disease [15] (fig. 2). Impairment of endothelial function results from changes in the expression and release of vasoactive mediators. Endothelium-derived $\mathrm{NO}$ is a potent vasodilator with antiproliferative properties synthesised by NO synthase, which is expressed constitutively in endothelial nitric oxide synthase (eNOS) cells. The expression of eNOS is reduced in pulmonary arteries of COPD patients with pulmonary hypertension [23] and also in smokers [24]. Interestingly in the latter group, the expression of eNOS was inversely correlated with endothelial function [24]. Prostacyclin, which is also synthesised by endothelial cells, exerts similar actions to NO. The expression of prostacyclin synthase is reduced in primary pulmonary hypertension [25]. At present there is no information about its expression in secondary forms of pulmonary hypertension. ET-1 is a potent vasoconstrictor released by endothelial cells that also exerts a mitogenic effect on arterial smooth muscle cells. Interestingly, part of ET-1 activity on smooth-muscle cells is mediated via an increase in reactive oxygen species production [26]. The expression of ET-1 in pulmonary arteries is increased in both primary and secondary forms of pulmonary hypertension [27]. In smokers with normal lung function the expression of ET-1 in the pulmonary artery does not differ from that in nonsmokers [24].

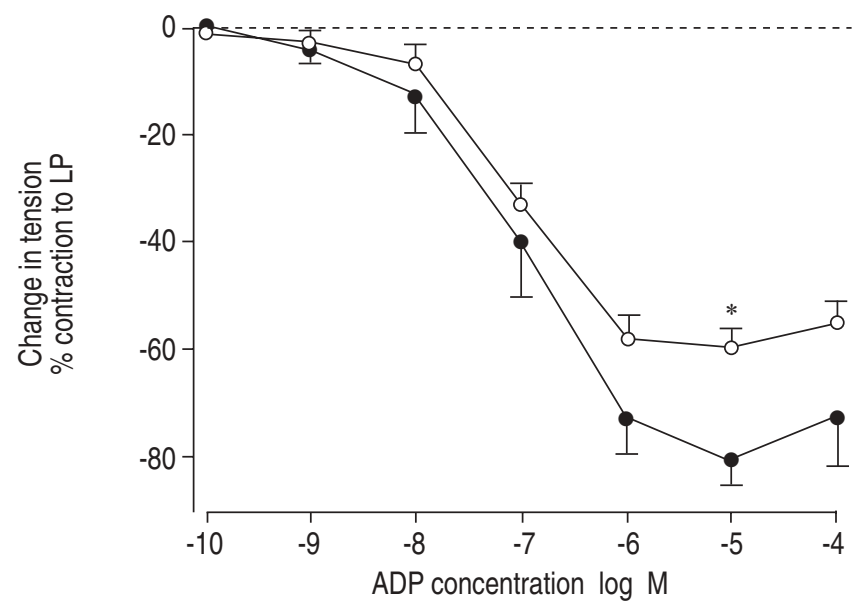

Fig. 2.-Changes in tension of pulmonary arteries, expressed as per cent reduction from precontraction with L-phenylephrine (LP), in response to cumulative concentrations of adenosine diphosphate (ADP), in patients with chronic obstructive pulmonary disease $(\bigcirc)$ and nonsmokers ()$^{*}$ : $\mathrm{p}<0.05$ compared with nonsmokers. 
Overall, these findings indicate that COPD endothelial dysfunction with changes in the expression and release of vasoactive mediators, that also regulate cell growth, should be regarded as a preliminary phenomenon that may serve as a base where additional factors may induce further changes in vascular structure and function. Indeed, alterations in endothelial function with inhibition of NO synthesis has been shown to upregulate the gene expression of growth factors, such as vascular endothelial growth factor, that promote cell proliferation and vessel remodelling in pulmonary hypertensive states [28, 29].

\section{Mechanisms of pulmonary vascular changes}

Chronic hypoxaemia. Pulmonary hypertension in disease states associated with decreased alveolar partial pressure of oxygen $\left(\mathrm{PO}_{2}\right)$ is considered to develop from persistent hypoxic vasoconstriction and subsequent vascular remodelling. The evidence for this arises from the similarities between the structural abnormalities of COPD and those occurring in natives who live at high altitudes [30], and in experimental animals kept in a low oxygen environment [31]. In vitro studies have also shown that hypoxia induces changes in the production and release of endothelium-derived vasoactive substances and promotes cell proliferation in the vascular wall, as well as an increased synthesis of extracellular matrix protein [32].

However, the potential role of hypoxaemia in COPD is being reconsidered in the last decade by several findings. First, studies performed in COPD patients have shown not only a wide variation in the individual responses of the pulmonary circulation to changes in inspired oxygen concentration [14, $33,34]$, but also a low correlation between $P \mathrm{a}, \mathrm{O}_{2}$ and $P$ pa [7]. Second, LTOT does not reverse pulmonary hypertension, although it prevents its progression [35]. Finally, structural abnormalities and endothelial dysfunction in pulmonary arteries can be observed, at least in part, in patients with mild COPD who do not have hypoxaemia and also in smokers with normal lung function $[14,15,36]$. These observations suggest that mechanisms other than hypoxaemia should be at the origin of pulmonary hypertension in COPD. Inflammation [14] and the effect of cigarette-smoke products [37] have been suggested as potential mechanisms that may contribute to the development of the structural and functional alterations of pulmonary circulation at early stages of COPD.

Inflammation. The idea of an inflammatory process as a mechanism of vascular remodelling arises from studies demonstrating a correlation between the severity of inflammatory infiltrate in small airways and the structural abnormalities of pulmonary muscular arteries [14]. Recent morphological studies show an increased number of inflammatory cells infiltrating the adventitia of pulmonary arteries of patients with COPD [36]. Such inflammatory infiltrate is largely constituted by activated T-lymphocytes, with a predominance of the CD8+ subset (fig. 3). The potential role of inflammation in the pathogenesis of pulmonary hypertension in COPD has not yet been established. However, inflammatory cells are a source of cytokines and growth factors that may target the endothelial cells and contribute to the development of structural and functional abnormalities of the vessel wall [38]. This hypothesis is consistent with the fact that the number of inflammatory cells infiltrating the wall of pulmonary arteries is inversely related to the endothelial function and directly related to the enlargement of the intimal layer [36]. Smokers with normal lung function also exhibit an increased number of CD8+ T-cells with a reduction of the CD4+/CD8+ ratio, as compared with nonsmokers [36]. This suggests that cigarette

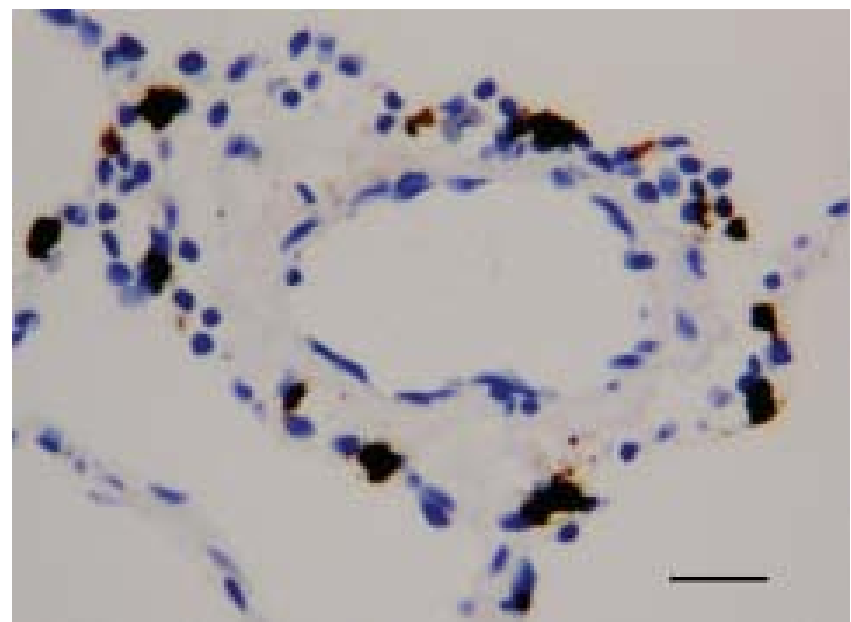

Fig. 3.-Photomicrograph of a pulmonary muscular artery from a patient with chronic obstructive pulmonary disease, immunostained with monoclonal antibody against CD8+. Positive cells (brown) are located in the adventitia. Internal scale bar $=42.2 \mu \mathrm{m}$.

smoking might induce inflammatory changes in pulmonary arteries at stages when there are no detectable alterations in the lung-function examination.

Cigarette smoking. The observation that some of the structural changes that affect pulmonary muscular arteries are also present in smokers with normal lung function [15] strongly suggests that cigarette-smoke products might exert a direct effect on vessel structure. This is in agreement with previous observations made by HALE et al. [20], who showed structural abnormalities in pulmonary muscular arteries of smokers as compared with nonsmokers, in a necropsic study.

It is well known that cigarette smoking is a risk factor for the development of vascular disease. Active and passive exposure to tobacco-smoke produces endothelial dysfunction in both coronary and systemic arteries. Exposure of pulmonary artery endothelial cells to cigarette- smoke extract causes an irreversible inhibition of eNOS activity, which is due to a diminished eNOS protein content and messenger ribonucleic acid [39]. Studies conducted in smokers also showed a reduced expression of eNOS in pulmonary arteries [24] (fig. 4). Significant abnormalities in pulmonary arteries (muscularisation of

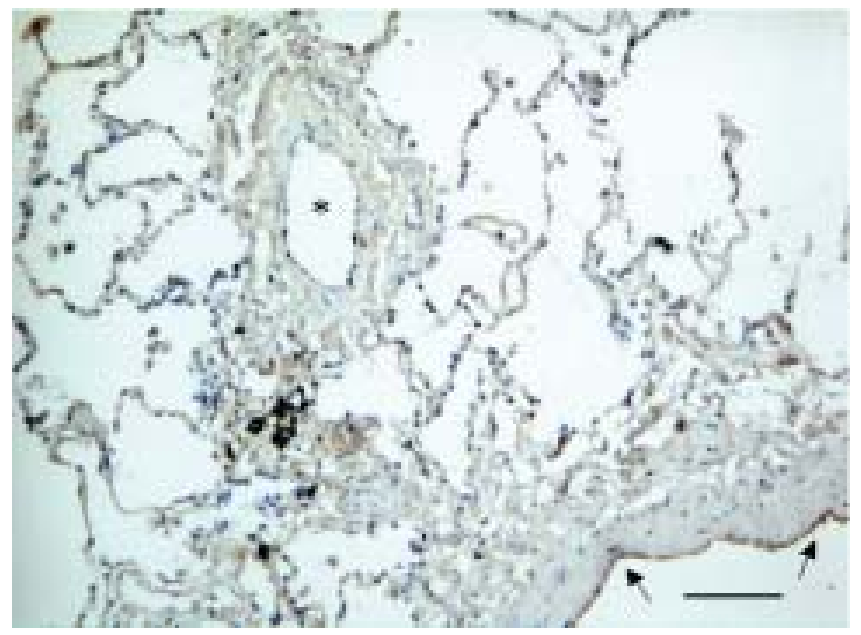

Fig. 4.-Immunohistochemical expression of endothelial nitric oxide synthase in a smoker's lung. *: Note the negative signal in a small pulmonary artery, whereas positive staining is apparent in a portion of a larger artery (arrows). Internal scale bar $=85.1 \mu \mathrm{m}$. 
precapillary vessels) have also been demonstrated in guinea pigs chronically exposed to cigarette smoke [37]. Interestingly, these vascular abnormalities were present when there was no evidence of emphysema, implicating that cigarette-smoke induced vascular abnormalities may antecede the development of pulmonary emphysema [40].

Accordingly, evidence suggests that the initial event in the natural history of pulmonary hypertension in COPD could be the lesion of pulmonary endothelium by cigarette-smoke products with the subsequent downregulation of eNOS expression and impairment of endothelial function. At this stage, the reactivity of pulmonary arteries to hypoxia might also be altered in some patients with mild COPD [16, 34, 41], hence contributing to alveolar ventilation/perfusion ratio $\left(V^{\prime} \mathrm{A} / Q^{\prime}\right)$ mismatching and promoting the development of arterial hypoxaemia. In this scenario, sustained exposure to hypoxaemia may induce further pulmonary vascular remodelling thus amplifying the initial effects of cigarette-smoke products (fig. 5).

\section{Physiopathology}

In COPD pulmonary hypertension is considered to be present when mean $P$ pa exceeds the upper normal limit of $2.66 \mathrm{kPa}(20 \mathrm{mmHg})[5,42]$. In general, the degree of pulmonary hypertension in COPD is of low-to-moderate magnitude, rarely exceeding $4.66-5.32 \mathrm{kPa}(35-40 \mathrm{mmHg})$. In a series of patients with severe emphysema, only $5 \%$ of the patients had mean $P$ pa $>4.66(35 \mathrm{mmHg})$ [7]. Furthermore, in a retrospective analysis of 600 patients referred for the study of pulmonary hypertension in a single institution, only five patients $(0.8 \%)$ had severe pulmonary hypertension $(P$ pa $>5.32 \mathrm{kPa}(40 \mathrm{mmHg}))$ associated with COPD [43]. Both right-atrial pressure and $P$ pcw tend to be normal, as does the cardiac output [1, 4, 42]. This haemodynamic profile contrasts with other causes of pulmonary hypertension (primary pulmonary hypertension, congenital heart disease, thromboembolic disease) where $P$ pa can reach extremely high values, close to those of the systemic circulation, and the cardiac output is usually reduced.

\section{Hypoxic pulmonary vasoconstriction}

Hypoxic stimulus exerts opposite actions on systemic and pulmonary circulation: dilates systemic arteries and constricts pulmonary arteries. Hypoxic vasoconstriction is thought to be responsible for restricting blood flow through the foetal pulmonary circulation before birth and for matching perfusion to

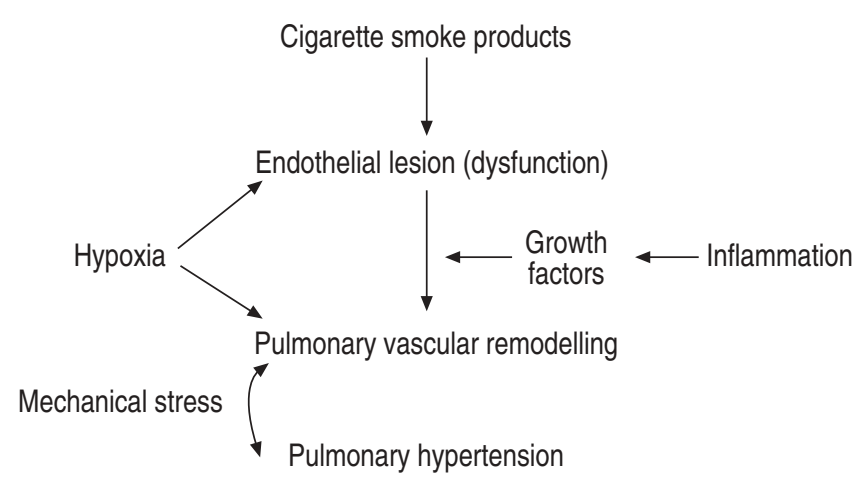

Fig. 5.-Pathophysiology of pulmonary hypertension in chronic obstructive pulmonary disease where cigarette-smoke products play a central role in initiating the sequence of changes which results in pulmonary hypertension. ventilation thereafter. Pulmonary arteriolar constriction in response to hypoxia reduces perfusion in poorly ventilated or nonventilated lung units and diverts it to better ventilated units, thereby restoring $V^{\prime} \mathrm{A} / Q^{\prime}$ equilibrium and hence increasing $\mathrm{Pa}, \mathrm{O}_{2}$. Hypoxic vasoconstriction plays an important role in matching blood flow to ventilation in chronic respiratory diseases, particularly in COPD where hypoxaemia and hypercapnia are due to $V^{\prime} \mathrm{A} / Q^{\prime}$ mismatching [44].

The effect of hypoxic pulmonary vasoconstriction on $V^{\prime} \mathrm{A} / Q^{\prime}$ relationships can be assessed using the inert-gas elimination technique, which allows the analysis and quantification of $V^{\prime} \mathrm{A} / Q^{\prime}$ relationships [45]. Worsening of $V^{\prime} \mathrm{A} / Q^{\prime}$ distributions during $100 \%$ oxygen breathing can be used as an estimate of the contribution of hypoxic vasoconstriction to $V^{\prime} \mathrm{A} / Q^{\prime}$ matching while breathing room air [14] (fig. 6). Using this approach it has been shown that in COPD the inhibition of hypoxic pulmonary vasoconstriction with oxygen breathing worsens $V^{\prime} \mathrm{A} / Q^{\prime}$ distributions in patients with different degrees of disease severity [44] (fig. 6). In general terms, the contribution of hypoxic vasoconstriction to $V^{\prime} \mathrm{A} / Q^{\prime}$ matching tends to be greater in patients with less severe COPD [14, 46]. Indeed, hypoxic pulmonary vasoconstriction is less active in patients with severe structural impairment of pulmonary muscular arteries [14]. Furthermore, in isolated pulmonary artery rings, it has been recently shown that the magnitude of contraction induced by hypoxic stimulus is inversely related to the endothelial
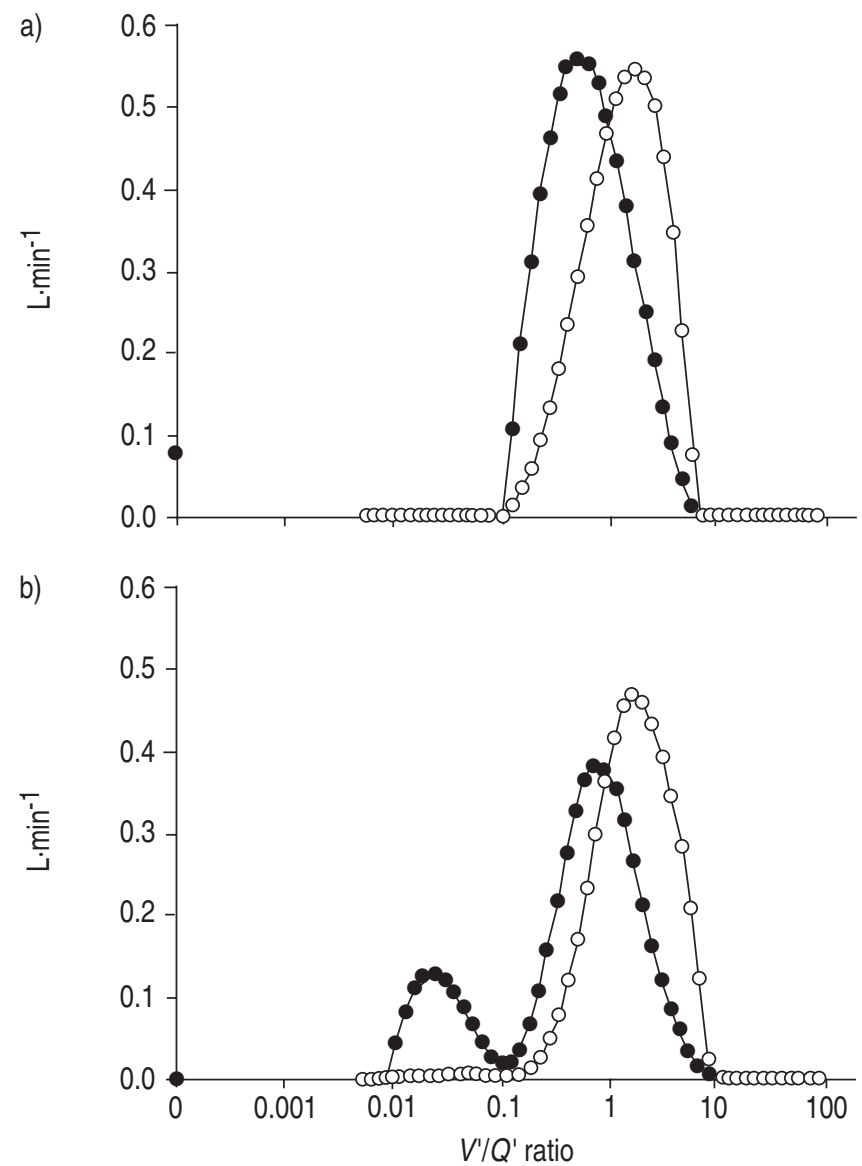

Fig. 6. - Alveolar ventilation/perfusion ratio $\left(V^{\prime} \mathrm{A} / Q^{\prime}\right)$ distributions in a patient with chronic obstructive pulmonary disease, recovered while breathing a) room air and b) 100\% oxygen. During 100\% oxygen breathing the $V^{\prime} \mathrm{A} / Q^{\prime}$ distribution became worse, as shown by increased perfusion in poorly ventilated alveolar units with low $V^{\prime} \mathrm{A} / Q^{\prime}$. Such an increase in $V^{\prime} \mathrm{A} / Q^{\prime}$ inequality is explained by the inhibition of hypoxic pulmonary vasoconstriction. $\bullet$ : Blood flow; $\bigcirc$ : ventilation. 
function and directly related to the arterial $\mathrm{PO}_{2}$ [41]. These findings suggest that the impairment of endothelial function is associated with an altered response to hypoxic stimulus that further worsens gas exchange. The contribution of hypoxic vasoconstriction to gas exchange in COPD should be taken into account when administering drugs that might potentially inhibit such a response since they may also impair gas exchange [47-50].

\section{Right-ventricular function}

Compared with the left ventricle, the right ventricle has a thinner wall, a greater ratio of volume-to-surface area and is less able to generate pressure. Accordingly, the right ventricle is considered a "volume" rather than a "pressure" pump. In physiological terms, the right ventricle is more able to adapt to changes in preload than to acute increases in afterload. Right ventricular ejection fraction (RVEF) decreases rapidly with acute increases in $P$ pa [51], whereas augmentation of preload by volume expansion does not change right-ventricular work [52].

In patients with COPD and pulmonary hypertension, the $P$ pa is not markedly elevated and the rate of progression of pulmonary hypertension is slow. Therefore, the right ventricle has time to adapt to such a modest increase in pressure load. When $P$ pa is chronically elevated the right ventricle dilates, with increases in both end-diastolic and end-systolic volumes. In COPD, the stroke volume of the right ventricle is usually maintained, whereas the ejection fraction is reduced. Subsequent hypertrophy of the right-ventricular wall in persistent pulmonary hypertension reduces its tension and hence the afterload.

The assessment of right-ventricular function is difficult and occasionally results in the misunderstanding of the rightventricular failure concept, in COPD. Systolic ventricular dysfunction is generally defined by a decrease in RVEF. In COPD, RVEF can be reduced and its value is inversely related to $P$ pa [53]. Nonetheless, a decrease in RVEF does not mean that there is true ventricular dysfunction [54]. The assessment of end-diastolic/pressure relationships allows a more accurate evaluation of right-ventricular contractility. Using this approach it has been shown that in clinically stable COPD patients the contractility of the right ventricle lies within normal limits, irrespective of the $P$ pa value $[55,56]$. However, during acute exacerbations, when $P$ pa increases markedly, the contractility of the right ventricle is reduced in patients with clinical signs of right-heart failure [57, 58].

In COPD the cardiac output is usually preserved and it might even rise during exacerbation episodes [59, 60], even when there are apparent signs of right-heart failure. Therefore, the usual definition of heart failure, as a reduction in cardiac output, does not apply in this condition. In fact, the true occurrence of right-heart failure in COPD has been questioned and there is controversy about the concept of cor pulmonale [57]. It has been proposed that the latter term should be abandoned in favour of a more precise definition based on the objective evidence of right-ventricular hypertrophy, enlargement, functional abnormality, or failure [57].

\section{Peripheral oedema}

Peripheral oedema may be a sign of venous congestion secondary to upstream transmission of right-ventricle filling pressures. However, in advanced COPD oedema is more related to hypercapnia rather than to raised jugular pressures [61, 62]. Some patients may present peripheral oedema without haemodynamic signs of right-heart failure or significant changes in
$P$ pa $[51,63]$. These findings have led to the reconsideration of peripheral-oedema formation in COPD [52, 57, 58, 62, 64].

Peripheral oedema in COPD results from a complex interaction between haemodynamic changes and the balance between oedema-promoting and oedema-protective mechanisms. In patients with pulmonary hypertension associated with chronic respiratory failure, hypoxaemia and hypercapnia may aggravate venous congestion inducing further activation of the sympathetic nervous system, which is already stimulated by right-atrial distension. Sympathetic activation decreases renalplasma flow, stimulates the renin-angiotensin-aldosterone system and promotes the tubular absorption of bicarbonate, sodium and water. Vasopressin also contributes to oedema formation. It is released when patients become hyponatraemic and vasopressin plasma levels are increased in patients with hypoxaemia and hypercapnia [52].

Atrial natriuretic peptide is released from distended atrial walls and it may act as an oedema-protective mechanism since it is a vasodilator, diuretic and natriuretic. Nevertheless its effects are usually insufficient to counterbalance the oedemapromoting mechanisms.

Peripheral oedema may develop or worsen during episodes of acute exacerbation. Analysing the changes from stable conditions that took place during an exacerbation episode, WeITZENBLUM et al. [60] identified a subgroup of patients with more marked peripheral oedema that was attributed to haemodynamic signs of right-heart failure (increase in end-diastolic pressure). Compared with patients with normal end-diastolic pressure, patients with right-heart failure had more marked increase in $P$ pa, as well as more severe hypoxaemia and hypercapnia. This suggests that worsening of pulmonary hypertension during exacerbations contributes to oedema formation.

\section{Exercise}

Exercise produces an abnormal increase in $P$ pa, especially in patients who have pulmonary hypertension at rest [4]. Patients that appear more prone to the development of pulmonary hypertension may show an abnormal increase in $P$ pa during exercise years before pulmonary hypertension is apparent at rest [13]. Different studies have identified a number of mechanisms for exercise-induced pulmonary hypertension in COPD, including hypoxic vasoconstriction, reduction of the capillary bed by emphysema, extramural compression by increased alveolar pressure or impaired release of endothelium-derived relaxing factors $[14,19,49$, 65 ] that may combine and contribute to the development of pulmonary hypertension during exercise. In COPD patients, $P$ pa during exercise is greater than predicted by the PVR equation, suggesting active pulmonary vasoconstriction on exertion [49]. The latter may be due to the enhancement of hypoxic pulmonary vasoconstriction by decreased mixedvenous $\mathrm{PO}_{2}$, increased tone of the sympathetic nervous system or decreased arterial $\mathrm{pH}$ [66]. During exercise, COPD patients may develop dynamic hyperinflation due to the expiratory flow limitation that results in increased alveolar pressure, which is transmitted to the $P$ pcw [67]. Furthermore increased ventilation during exercise, in the presence of airflow obstruction, results in significant swings of intrathoracic pressure. These changes in pressure may reduce cardiac output by altering systemic venous return or by increasing left-ventricular afterload [68]. Impairment of endothelial release of vasorelaxing agents like NO may also contribute to an impaired dilator response to increases in flow [69]. However, in a group of COPD patients who developed pulmonary hypertension during exercise, the exogenous supply of NO did not block the abnormal increase in $P$ pa, suggesting that the defective 
release of NO is not a major player in exercise-induced pulmonary hypertension in COPD [70].

Since pulmonary hypertension may develop at moderate levels of exercise it has been suggested that repeated episodes of pulmonary hypertension during daily activities for example climbing stairs or even walking, could contribute to the development of right-ventricular hypertrophy [71].

\section{Assessment of pulmonary hypertension in chronic obstructive pulmonary disease}

Recognition of pulmonary hypertension in COPD is difficult, especially in its mildest form. Symptoms due to pulmonary hypertension, such as dyspnoea or fatigue, are difficult to differentiate from the clinical picture of COPD. Furthermore, the identification of some clinical signs may be obscured by chest hyperinflation or the large swings in intrathoracic pressure. Usually, the main suspicion is based in the presence of peripheral oedema, but, as discussed earlier, this may not be a sign of right-ventricular failure in COPD. Cardiac sounds may be disturbed by the presence of bronchial rales or overinflated lungs. Therefore, the typical auscultatory findings of pulmonary hypertension (ejection click or increased pulmonary component of the second heart sound and pansystolic murmur of tricuspid regurgitation) are uncommon in COPD patients.

\section{Conventional examinations}

Chest radiography. The most characteristic radiographical pattern of pulmonary hypertension is the increase of the vascular hilium size with oligohaemia in the peripheral lung fields. Other signs of pulmonary hypertension are cardiomegaly, due to an enlarged right ventricle and an enlarged pulmonary trunk. Widening of the hilium can be estimated by the hiliar thoracic index, which is defined by the ratio of the transhiliar width (distance between the start of divisions of the right and left main pulmonary arteries) to the transverse diameter of the thorax [72]. A ratio $>0.36$ suggests pulmonary hypertension $[72,73]$. Another potential indicator in the chest radiography is the widening of the descending right pulmonary artery diameter (usually $<16 \mathrm{~mm}$ ) to $>18 \mathrm{~mm}$. The enlarged right ventricle accounts for an increased cardiothoracic ratio $>0.5$ together with encroachment of the retrosternal airspace on a lateral film. However, it must be noted that these radiological signs may be difficult to identify in COPD.

Electrocardiogram. The sensitivity of the electrocardiogram to detect right-ventricular hypertrophy is relatively low and electrocardiographic changes are not closely related to the severity of pulmonary hypertension [73]. Electrocardiographical changes associated with cor pulmonale include: 1) a P-pulmonale pattern suggesting right-atrial overload in leads II, III and aVF; 2) an $\mathrm{S}_{1} \mathrm{~S}_{2} \mathrm{~S}_{3}$ pattern; 3) an $\mathrm{S}_{1} \mathrm{Q}_{3}$ pattern; 4) incomplete right-bundle-branch block; 5) right-ventricular hypertrophy, as defined by a QRS axis of $\geqslant+120^{\circ}$, a predominant $\mathrm{R}$ wave in $\mathrm{V} 1$, or a R/S amplitude ratio in V 5 and V6 $<1$ (at least two of these three criteria are sufficient to raise suspicion of rightventricular hypertrophy); and 6) low-voltage QRS [11, 73]. INCALZI et al. [11] assessed the prognostic value of these electrocardiographical changes in 217 patients with COPD, who were followed up to 13 yrs after an exacerbation episode. Both the $S_{1} S_{2} S_{3}$ pattern and signs of right-atrial overload were associated with shorter survival rates [11], further supporting the notion that pulmonary hypertension has a strong influence on COPD outcome. OSWALD-MAMMOSER et al. [74] compared the sensitivity and specificity of different noninvasive techniques for predicting the presence of pulmonary hypertension in COPD. Electrocardiographical changes had a specificity of $86 \%$ and a sensitivity of $51 \%$ in detecting pulmonary hypertension. These values compared favourably with chest radiographies [74]. Given the simplicity and low cost of electrocardiography, it is recommended to use it to identify those patients more likely to suffer pulmonary hypertension.

Lung-function testing. Lung-function tests are necessary for the diagnosis of COPD. Unfortunately, there are no specific patterns of pulmonary function impairment associated with the development of pulmonary hypertension. Pulmonary hypertension has little effect per se on lung mechanics or gas exchange. In conditions of preserved lung parenchyma, pulmonary hypertension can reduce carbon monoxide diffusion capacity of the lung $(D \mathrm{~L}, \mathrm{CO})$. However, in COPD the decrease of $D \mathrm{~L}, \mathrm{CO}$ cannot be attributed to pulmonary hypertension since it can be explained by lung emphysema.

\section{Echocardiography}

Echocardiography is an important diagnostic step in any patient with suspected pulmonary hypertension. It is a noninvasive technique, easily available, that allows the assessment of right-ventricular hypertrophy and/or dilatation, ejectionflow dynamics and may also provide an estimate of pulmonary artery pressure [75]. However, this method presents technical difficulties in COPD patients because overinflated chests may alter sound-wave transmission.

Two-dimensional echocardiography provides information on the morphology and dynamics of cardiac structures and it is also essential for the diagnosis of associated left-heart disease. Typical signs of cor pulmonale are right ventricular and atrial enlargement with a normal or reduced left-ventricular cavity and eventually reversal of the normal septal curvature. In the presence of tricuspid regurgitation, continuous-wave Doppler echocardiography may provide an estimate of systolic $P$ pa. However, tricuspid regurgitation is not always present in COPD, the incidence ranges between $24-66 \%$ of patients [75-77], therefore limiting the possibility to estimate $P$ pa in a number of patients.

Using exercise echocardiography it has been possible to identify an abnormal ventricular-septal motion with distortion of the left ventricle in COPD patients. This finding may help to detect occult right-ventricular dysfunction [78].

BURGESS et al. [10] have evaluated the prognostic value of echocardiographic assessments of right-ventricular function in 87 patients with COPD. These authors have shown that both right-ventricular end-diastolic diameter index and velocity of late diastolic filling, were independent predictors of survival [10]. These indices have high feasibility, even in patients with marked lung hyperinflation.

On the basis of the information that echocardiography provides on the function of the right ventricle and its prognostic relevance, its use is strongly recommended for the assessment of pulmonary hypertension in COPD.

\section{Transcutaneous Doppler jugular venous flow}

MAtsuYama et al. [79] have recently demonstrated that transcutaneous measurement of jugular vein flow velocity by echo Doppler may have a potential role in the prediction of pulmonary artery pressure in COPD patients. The measurement is noninvasive and feasible in all patients. This method is based on the measurement of diastolic and systolic flow velocity of jugular venous pulse. In a group of 64 COPD patients, the ratio of diastolic to systolic flow was significantly 
correlated with $P$ pa measured at right-heart catheterisation and had higher specificity in detecting pulmonary hypertension than other echographic methods [79]. Limitations of this method include a low sensitivity in patients with mild pulmonary hypertension, and potential technical errors in the presence of tachycardia or arrhythmia.

\section{Magnetic resonance imaging}

New generations of magnetic resonance imaging scanners offer great promise in the diagnosis of pulmonary hypertension and altered right-ventricular structure and function. Pulmonary magnetic resonance angiography is a noninvasive imaging modality, the usefulness of which is currently under evaluation for the identification of patients with acute or chronic pulmonary hypertension. It has been shown that a right pulmonary artery diameter $>28 \mathrm{~mm}$ is sensitive and highly specific for the prediction of pulmonary hypertension [80]. However, its application in COPD has not yet been evaluated.

\section{Exercise testing}

Cardiopulmonary exercise testing provides useful information for the assessment of the functional physical impairment in COPD. Ventilatory impairment is the major limiting factor of exercise tolerance in COPD [81]. The role of cardiovascular factors as cause of exercise limitation is thought to be minimal in COPD, considering that alterations in ventilatory mechanics impede patients to exercise intensely enough to achieve cardiac limitation. Nevertheless, an abnormal haemodynamic response cannot be disregarded as a potential mechanism contributing to exercise limitation in these patients. Cardiopulmonary exercise testing, with measurements of heart rate, blood pressure, ventilatory variables at increasing workload, for the determination of lactic threshold and peak oxygen consumption, provides information on the potential contribution of cardiovascular dysfunction to exercise intolerance. The oxygen pulse, which is the oxygen consumption divided by the heart rate, has been used as an estimator of stroke volume, and hence of cardiac function. The oxygen pulse at peak exercise is usually reduced in patients with COPD and its value correlates with the exercise capacity $[68,82,83]$. Indeed, some investigators have suggested that oxygen pulse is a major determinant of the exercise capacity in COPD [82]. Recently, Mічамото et al. [84] have identified patterns of dysfunction at cardiopulmonary exercise test in patients with primary pulmonary hypertension. To what extent some of these alterations could also be recognised in COPD has not been established yet.

Timed walking tests, for example the 6-min walking test, are simpler than the conventional incremental cycling protocols and have been used in the clinical evaluation of patients with COPD [12, 85, 86] and primary pulmonary hypertension [84]. The results of timed-walking tests have prognostic value in both conditions [84, 87], and are sensitive to changes after therapeutic interventions [88]. Indeed, in patients with primary pulmonary hypertension the distance walked during the 6 min has been used as a major outcome to assess the efficacy of new treatments in multicentric trials [89]. Considering the results of these trials it would be interesting to evaluate to what extent cardiovascular impairment might influence the results of timed walking tests and whether these tests might be sensitive enough for the assessment of pulmonary hypertension treatment in patients with COPD and pulmonary hypertension.

\section{Analysis of expired air}

Endogenous NO plays an important role in the regulation of vascular tone. As indicated above, patients with COPD have an impaired release of NO in pulmonary arteries. NO derived from the lungs can be analysed in expired air. Changes in the NO concentration in expired air have been identified in different respiratory disorders and it has been suggested that expired NO may be a useful marker of disease activity in some conditions [90]. The presence of pulmonary hypertension has been associated with lower NO output both at rest [91] and during exercise [92]. In patients with heart failure and pulmonary hypertension, expired NO is negatively correlated with PVR [92]. Studies of expired NO concentration in COPD have provided diverging results [90]. There is some evidence, however, that the concentration of NO in expired air is lower in patients with more severe COPD. CLINI et al. [93] investigated the relationship between expired NO and right-ventricular function in a group of 34 patients with COPD, showing that echocardiographic estimates of $P$ pa and right-ventricular function were significantly correlated with expired NO concentration. Patients with right-ventricular dysfunction had lower NO concentration in expired air, suggesting that these patients might have either an impaired release or reduced diffusion of NO from the endothelium into the airways [93]. It should be noted, however, that the exact origin of NO in expired air is uncertain. Nonetheless, the idea that markers of endothelial function could be analysed in expired air and this might provide information about pulmonary vascular function [93] is attractive and should deserve further investigation.

\section{Right-heart catheterisation}

Right-heart catheterisation is the gold standard for the diagnosis of pulmonary hypertension. The procedure allows direct measurements of $P$ pa, cardiac output and pulmonary vascular resistance. It can be also used to assess the acute effects of therapeutic interventions. Right-heart catheterisation is a safe procedure in expert hands, however, because of its invasive nature, it is not routinely recommended in the assessment of patients with COPD. Nevertheless, in selected cases right-heart catheterisation might be indicated: patients with severe pulmonary hypertension (i.e. echocardiographical estimated systolic $P$ pa $>6.65 \mathrm{kPa}(50 \mathrm{mmHg}))$ that might benefit from treatment with prostacyclin [43], patients with frequent episodes of right-ventricular failure, and in the preoperative evaluation of candidates to lung transplant or lung volume reduction surgery (LVRS) [94].

\section{Treatment}

\section{Vasodilators}

Treatment with vasodilators (i.e. calcium-channel blockers) improves symptoms, exercise tolerance and survival in patients with pulmonary arterial hypertension [95]. Accordingly, there is a rationale for the use of vasodilators in COPD in order to decrease $P$ pa and improve both right-ventricular function and oxygen delivery, as these effects might increase exercise tolerance and eventually, survival.

Calcium-channel blockers have been extensively evaluated for the treatment of pulmonary hypertension in COPD. The acute administration of nifedipine has been shown to reduce $P$ pa and increase cardiac output in COPD patients, studied both at rest and during exercise [49, 50, 96]. However, nifedipine inhibits hypoxic pulmonary vasoconstriction [97] 
and in COPD this effect worsens $V^{\prime} \mathrm{A} / Q^{\prime}$ relationships and lowers arterial $\mathrm{PO}_{2}[47,49]$. The changes in $V^{\prime} \mathrm{A} / Q^{\prime}$ distributions before and after the administration of $20 \mathrm{mg}$ of nifedipine, in a patient with COPD, is shown in fig. 7. The administration of nifedipine increased perfusion in poorly ventilated lung units with low $V^{\prime} \mathrm{A} / Q^{\prime}$ ratios that resulted in a lower $\mathrm{Pa}, \mathrm{O}_{2}$. This indicates that nifedipine suppressed the beneficial effect of hypoxic pulmonary vasoconstriction on $V^{\prime} \mathrm{A} / Q^{\prime}$ matching. Similar effects of nifedipine have been shown in exercise-induced pulmonary hypertension. AGUSTí et al. [49] showed that nifedipine reduced the increase in PVR, induced by exercise, but simultaneously it worsened $V^{\prime} \mathrm{A} / Q^{\prime}$ distributions and arterial oxygenation. The deleterious effect of vasodilators on $V^{\prime} \mathrm{A} / Q^{\prime}$ distributions in COPD has also been shown with felodipine [98], atrial natriuretic factor [99] and acetylcholine [100].

Clinical results of long-term treatment with calcium-channel blockers in COPD have been disappointing. Despite observation in some studies of slight haemodynamic improvement [101], other studies showed both pulmonary haemodynamics and clinical status either deteriorated or remained unchanged after several weeks or months of treatment $[102,103]$.

Overall, it can be concluded that despite systemic vasodilators may produce a slight reduction in $P$ pa and an increase in cardiac output in COPD, their administration is usually accompanied by a worsening in gas exchange. Furthermore there is no evidence that long-term treatment with systemic
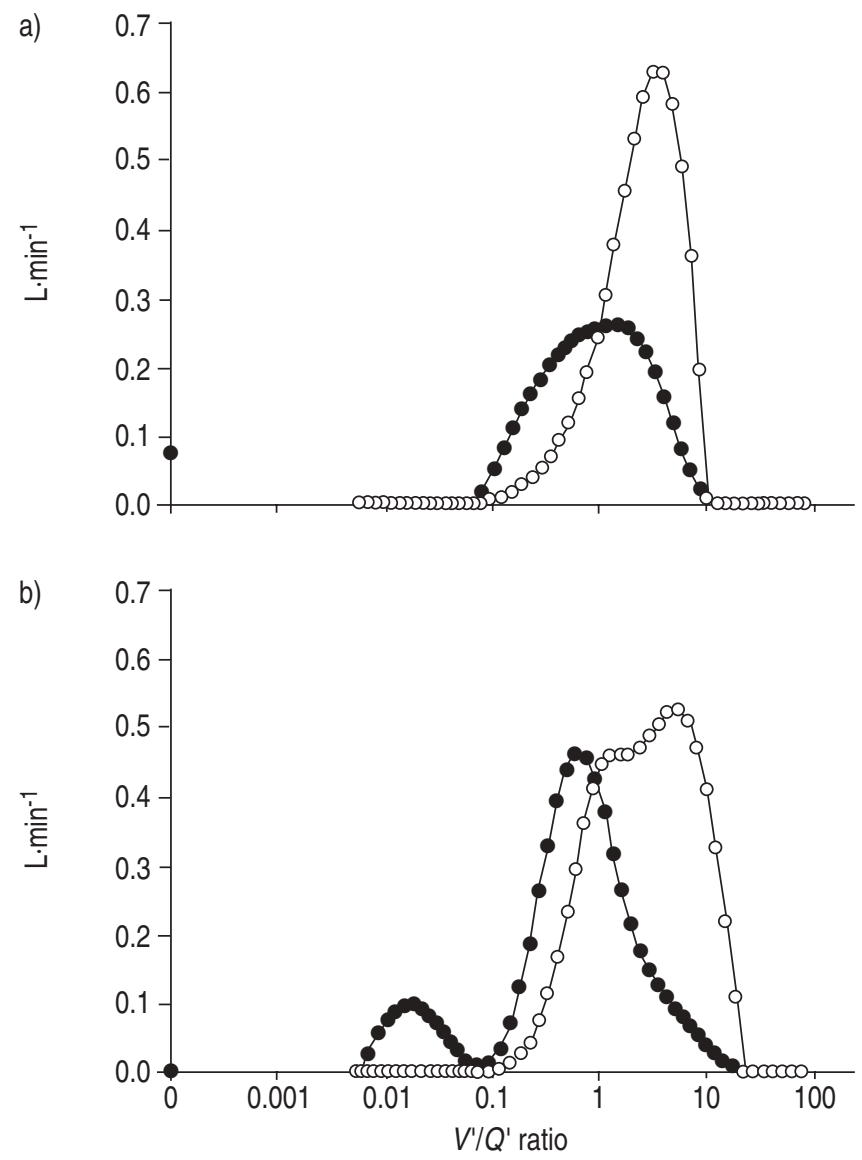

Fig. 7.- Ventilation/perfusion ratio $\left(V^{\prime} \mathrm{A} / Q^{\prime}\right)$ distributions in a patient with COPD, obtained a) before and b) after administering $20 \mathrm{mg}$ of nifedipine. Note the increase in $V^{\prime} \mathrm{A} / Q^{\prime}$ mismatch (increase in perfusion of lung units with low $V^{\prime} \mathrm{A} / Q^{\prime}$ ) after nifedipine, which resembles that shown during $100 \%$ oxygen breathing (fig. 6). Blood flow; $\bigcirc$ : ventilation. vasodilators is of clinical benefit. For these reasons vasodilators are not recommended for the treatment of pulmonary hypertension associated with COPD [104].

\section{Selective pulmonary vasodilators}

When administered by inhalation, NO acts as a selective vasodilator of the pulmonary circulation. This is due to NO inactivation when combined with haemoglobin, which it has a very high affinity for. The effect of inhaled NO in COPD has been evaluated by several investigators. When inhaled NO is administered in low concentrations it does not seem to exert any effect on gas exchange, whereas it decreases pulmonary arterial pressure in a dose-dependent manner [100]. When administered in high concentrations (i.e. 40 parts per million (ppm)), it usually decreases $P$ pa and exerts variable effects on gas exchange $[46,100]$, although in general terms it usually decreases $\mathrm{Pa}_{\mathrm{a}} \mathrm{O}_{2}[46,70,105]$. Such a deleterious effect on gas exchange results from worsening of $V^{\prime} \mathrm{A} / Q^{\prime}$ distributions, as shown by an increased perfusion in poorly ventilated lung units with low $V^{\prime} \mathrm{A} / Q^{\prime}$ ratio [46]. This finding is consistent with inhibition of hypoxic pulmonary vasoconstriction by NO [106] in poorly ventilated alveolar units to which the gas has access too. Nitric oxide inhalation does not modify intrapulmonary shunt, which is rather small in COPD.

Interestingly, the effects of inhaled NO on gas exchange are different during exercise than at rest. ROGER et al. [70] showed that in COPD patients, inhaled NO decreased pulmonary vascular resistance both at rest and during exercise. However, whereas $\mathrm{Pa}, \mathrm{O}_{2}$ decreased during exercise whilst breathing room air, no change was shown during NO inhalation. Furthermore, at rest $\mathrm{NO}$ inhalation worsened $V^{\prime} \mathrm{A} / Q^{\prime}$ distributions, while during exercise it promoted better $V^{\prime} \mathrm{A} / Q^{\prime}$ matching, as shown by lesser perfusion in units with low $V^{\prime} \mathrm{A} / Q^{\prime}$ ratio [70]. Such a different effect of inhaled NO during exercise might be explained by enhanced distribution of the gas to well ventilated lung units with faster time constants, which are more efficient in terms of gas exchange.

In clinical terms, these findings may imply that if inhaled NO could be delivered specifically to well ventilated alveolar units with fast time constants, the beneficial vasodilator effect of NO would not be offset by its deleterious impact on gas exchange. This notion has led to the development of the so-called "spiked" delivery of NO [107]. With this system, a small bolus of NO is administered at the beginning of inspiration, with the aim that it will be specifically distributed to alveolar units with fast time constants. Further, the spiked delivery of NO reduces remarkably the total amount of NO delivered to the patient [107]. SIDDONS et al. [108] have shown that, contrasting with the worsening of $V^{\prime} \mathrm{A} / Q^{\prime}$ distributions induced by continuous administration of NO, the spiked delivery resulted in better $V^{\prime} \mathrm{A} / Q^{\prime}$ matching.

To compensate for the potential deleterious effect of inhaled NO on gas exchange in COPD, different investigators have evaluated the effects of the simultaneous administration of NO and oxygen. YoshidA et al. [109] showed that the combined administration of low doses of $\mathrm{NO}$ and oxygen resulted in a significant improvement of pulmonary haemodynamics and provided better oxygenation than when breathing oxygen alone. Whereas the haemodynamic effects of combined NO and oxygen appear to be related to the NO dose, the amelioration in gas exchange seems to have a ceiling effect at a concentration of $5 \mathrm{ppm}$ [110]. AsHuTOSH et al. [111] showed that inhaled NO can be safely administered to COPD patients for $24 \mathrm{~h}$. Nevertheless, the long-term administration of NO combined with oxygen is not easy and there is no evidence that it ameliorates pulmonary hypertension in COPD. 


\section{Long-term oxygen therapy}

In patients with COPD, chronic hypoxaemia plays a key role in the development of pulmonary hypertension. Therefore, correction of alveolar hypoxia with supplemental oxygen seems appropriate for treating pulmonary hypertension in COPD. Acute administration of oxygen in patients with advanced COPD at rest has little effect on pulmonary haemodynamics $[46,58,112]$ or on right ventricular ejection fraction [56] in patients studied under stable clinical conditions. During acute exacerbation episodes, when $P$ pa increases significantly, controlled administration of oxygen also results in minimal or no change of $P$ pa $[112,113]$. By contrast, when oxygen is administered during exercise it often improves pulmonary haemodynamics [4] and RVEF [114].

The administration of LTOT has been shown to improve survival in COPD patients with chronic hypoxaemia. In the two classical studies that showed survival benefits in patients treated with LTOT, the Medical Research Council (MRC) [115] and the Nocturnal Oxygen Therapy Trial (NOTT) [116], pulmonary haemodynamic measurements were performed before initiating LTOT and after a long period of follow-up. In the MRC study, $P$ pa remained unaltered in patients receiving LTOT $\left(>15 \mathrm{~h} \cdot \mathrm{day}^{-1}\right)$, whereas in the control group $P$ pa rose by a mean of $0.36 \mathrm{kPa}(2.7 \mathrm{mmHg}) \cdot \mathrm{yr}^{-1}$ [115]. In the NOTT study, 117 patients were re-evaluated after 6 months of treatment. Whereas in patients receiving continuous LTOT $\left(>18 \mathrm{~h} \cdot\right.$ day $\left.^{-1}\right) \quad P$ pa decreased by an average of $0.05 \mathrm{kPa}$ $(0.399 \mathrm{mmHg})$, it did not change in the group receiving nocturnal LTOT $\left(10-12 \mathrm{~h} \cdot \mathrm{day}^{-1}\right)$ [116]. It should be noted that despite the haemodynamic improvement shown in some patients, in the majority of them $P$ pa values recorded in the follow-up study did not return to normal levels. These results indicate that LTOT may slow down the evolution of pulmonary hypertension in COPD and that it might even reverse its progression when oxygen is administered continuously. Nevertheless, both the MRC and the NOTT studies showed that the decrease in mortality in patients receiving LTOT was not related to changes in pulmonary haemodynamics [115, 116]. Indeed, the NOTT study clearly demonstrated that ameliorating pulmonary hypertension did not result in improved mortality [116].

The beneficial effects of LTOT on the progression of pulmonary hypertension in COPD were confirmed by WEITZENBLUM et al. [35] in a small group of patients who were followed for long periods of time before and after initiating LTOT. Before the onset of LTOT, $P$ pa rose by an average of $0.20 \mathrm{kPa}$ $(1.5 \mathrm{mmHg}) \cdot \mathrm{yr}^{-1}$. By contrast, patients receiving LTOT showed a progressive decrease of $P$ pa $\left(-0.29 \mathrm{kPa}(-2.2 \mathrm{mmHg}) \cdot \mathrm{yr}^{-1}\right)$ [35]. It should be noted, however, that despite this improvement the normalisation of $P$ pa was rarely observed in the study performed 31 months after initiating LTOT [35]. Furthermore, necropsic studies have failed to show significant differences in the structural abnormalities of pulmonary vessels in patients receiving LTOT for long periods of time, when compared with patients who did not receive oxygen treatment [17].

Considering that the haemodynamic response to oxygen administration might be widely variable in COPD, AsHUTOSH et al. [34] evaluated the long-term effects of oxygen therapy according to its acute effects on pulmonary haemodynamics. These authors showed that survival benefit of LTOT was greater in patients who showed a significant decrease in $P$ pa during the acute administration of oxygen (acute responders) [34].

In summary, LTOT appears to be the more appropriate treatment for pulmonary hypertension in hypoxaemic COPD patients as its administration slows down and sometimes reverses, the progression of pulmonary hypertension. Nevertheless, $P$ pa rarely returns to normal values and the structural abnormalities of pulmonary vessels remain unaltered. It is likely that, in agreement with other forms of pulmonary hypertension [95], a subgroup of patients who are acute responders to oxygen administration might obtain greater benefit from LTOT.

\section{Diuretics}

Diuretics are usually administered to COPD patients with peripheral oedema in order to reduce sodium and water retention and hence right-ventricular workload. Nevertheless, diuretics should be given with care as they may induce metabolic alkalosis that could aggravate arterial hypercapnia [117]. Furthermore, excessive intravascular volume depletion might compromise adequate filling of the afterloaded right ventricle and promote further blood viscosity in polycytemic patients [73]. Diuretic treatment is usually instituted with low doses of loop diuretics, such as furosemide $\left(20-40 \mathrm{mg} \cdot \mathrm{day}^{-1}\right)$. Monitoring of plasma electrolyties is mandatory and potassium or magnesium supplementation may be necessary.

\section{Other treatments}

Digitalis. Digitalis has been used for the management of cor pulmonale for many years. However, there is no evidence to support the use of cardiac glycosides in the treatment of cor pulmonale unless there is concurrent left-ventricular failure [118] or atrial fibrillation [119]. Furthermore, cardiac glycosides can induce pulmonary vasoconstriction [52] and the risk of digitalis toxicity is increased in patients with arterial hypoxaemia or diuretic-induced hypokalaemia.

Bronchodilators. These may exert some beneficial effects on pulmonary haemodynamics in patients with COPD.

Theophylline. This slightly reduces pulmonary vascular resistance and improves both right- and left- ventricular ejection fractions [120]. Nevertheless, patients with right ventricular failure have decreased clearance of theophylline and their plasma levels should be closely controlled.

$\beta$-adrenergic agonists. These are given intravenously and exert little effect on $P$ pa. Nevertheless, they increase cardiac output and ventricular performance and as a result, usually reduce PVR [121, 122]. However, these effects are frequently accompanied by worsening of arterial oxygenation, due to the inhibitory effect of these drugs on hypoxic pulmonary vasoconstriction $[48,122]$. Such a detrimental effect of $\beta$-adrenergic agonists on gas exchange are not seen when they are administered by inhalation [122].

Phlebotomy. This has been used to reduce blood volume and viscosity in polycytaemic patients with COPD and pulmonary hypertension. In patients with haematocrit levels $>55 \%$, reduction of this value by $>10 \%$ resulted in a significant decrease of PAP and PVR and improved exercise capacity [123, 124]. Nevertheless, nowadays with the regular use of LTOT in patients with chronic respiratory failure, haematocrit values $>50-55 \%$ are infrequently seen.

\section{Lung volume reduction surgery}

LVRS is an alternative treatment to reduce respiratory symptoms in patients with severe emphysema [125]. Severe 
pulmonary hypertension $(\mathrm{Ppa}>4.66 \mathrm{kPa}(35 \mathrm{mmHg}))$ is usually considered an exclusion criteria for the procedure, considering that it reflects lack of "recruitable" lung parenchyma. LVRS improves pulmonary function, dyspnoea sensation, exercise and quality of life [125]. The effects of LVRS on pulmonary haemodynamics have been analysed occasionally. WEG et al. [126] reported an increase of $P$ pa after LVRS, which was attributed to the reduction of pulmonary capillary bed. Contrasting with this, SCIURBA et al. [127] showed an improvement in right-ventricular systolic function. Such an improvement was attributed to capillary recruitment in lung units previously compressed by hyperinflated alveoli, greater tethering of extraalveolar vessels as a consequence of improved elastic recoil, or increased right-ventricular preload as a result of reduced intrathoracic pressures.

OSWALD-MAMMOSSER et al. [128] studied pulmonary haemodynamics in a group of patients with advanced COPD before and after LVRS. In their study resting $P$ pa remained unaltered after LVRS, whereas exercise $P$ pa decreased slightly, yet not significantly [128]. Interestingly, after LVRS there was a significant reduction of the respiratory swings of diastolic pressure, both at rest and during exercise. Indeed, the change in $P$ pa was significantly related to the change in transdiaphragmatic pressure [12]. Accordingly, the authors postulated that the improvement in respiratory mechanics after LVRS, with the subsequent decrease of respiratory swings would exert a beneficial effect on pulmonary blood flow distribution and also on both right- and left-ventricular performances, especially during exercise [128]. Furthermore, in this study the improvement in arterial oxygenation during exercise after LVRS was closely correlated with the improvement in exercise $P$ pa, whereas it was unrelated to changes in FEV1 [128]. This suggests that LVRS modifies the distribution of pulmonary blood flow in a way that is more efficient for gas exchange [129].

\section{New pathogenic approaches}

Experience accumulated in primary pulmonary hypertension and other forms of pulmonary arterial hypertension suggests that treatments addressed to correct the fundamental disturbance that produces pulmonary hypertension, namely endothelial dysfunction, might reverse, to some extent, its progression [130]. In this regard, the administration of prostacyclin, its synthetic analogues, or the endothelin-receptor antagonist bosentan [89], has provided excellent results in pulmonary arterial hypertension that have been attributed to the regression of vascular remodelling. Considering this experience and taking into account that the pathogenesis of pulmonary hypertension in COPD shares common pathways with that of primary pulmonary hypertension, it is conceivable that drugs, which may correct the endothelial vasoconstrictor-dilator imbalance, could be of clinical benefit [66]. Indeed, patients with pulmonary hypertension associated with idiopathic pulmonary fibrosis have been treated with prostacyclin analogues [131] or sildenafil [132], a selective phosphodiesterase-5 inhibitor that enhances the action of endothelial NO, with encouraging results. To what extent this approach might also be useful for the treatment of pulmonary hypertension associated with COPD remains unsettled.

Presently there are drugs available that may be active at the pathogenic mechanistic level of pulmonary hypertension and are easy to administer. Therefore, their potential role in the treatment of pulmonary hypertension, associated with chronic obstructive pulmonary disease, deserves further attention.

\section{References}

1. Fishman AP. State of the art: chronic cor pulmonale. Am Rev Respir Dis 1976; 114: 775-794.

2. Weitzenblum E, Kessler R, Oswald M, Fraisse Ph. Medical treatment of pulmonary hypertension in chronic lung disease. Eur Respir J 1994; 7: 148-152.

3. Pietra GG. Pathology of the pulmonary vasculature and heart. In: Cherniack NS, ed. Chronic obstructive pulmonary disease. Philadelphia, W.B. Saunders, 1991; pp. 21-26.

4. Burrows B, Kettel LJ, Niden AH, Rabinowitz M, Diener CF. Patterns of cardiovascular dysfunction in chronic obstructive lung disease. N Engl J Med 1972; 286: 912-918.

5. Weitzenblum E, Hirth C, Ducolone A, Mirhom R, Rasaholinjanahary J, Ehrhart M. Prognostic value of pulmonary artery pressure in chronic obstructive pulmonary disease. Thorax 1981; 36: 752-758.

6. Weitzenblum E, Sautegeau A, Ehrhart M, Mammosser M, Hirth C, Roegel E. Long-term course of pulmonary arterial pressure in chronic obstructive pulmonary disease. Am Rev Respir Dis 1984; 130: 993-998.

7. Scharf SM, Iqbal M, Keller C, Criner G, Lee S, Fessler HE. Hemodynamic characterization of patients with severe emphysema. Am J Respir Crit Care Med 2002; 166: 314-322.

8. Traver GA, Cline MG, Burrows B. Predictors of mortality in chronic obstructive pulmonary disease. A 15-year follow-up study. Am Rev Respir Dis 1979; 119: 895-902.

9. Oswald-Mammosser M, Weitzenblum E, Quoix E, et al. Prognostic factors in COPD patients receiving long-term oxygen therapy. Importance of pulmonary artery pressure. Chest 1995; 107: 1193-1198.

10. Burgess MI, Mogulkoc N, Bright-Thomas RJ, Bishop P, Egan JJ, Ray SG. Comparison of echocardiographic markers of right ventricular function in determining prognosis in chronic pulmonary disease. J Am Soc Echocardiogr 2002; 15: 633-639.

11. Incalzi RA, Fuso L, De Rosa M, et al. Electrocardiographic signs of chronic cor pulmonale: A negative prognostic finding in chronic obstructive pulmonary disease. Circulation 1999; 99: 1600-1605.

12. Kessler R, Faller M, Fourgaut G, Mennecier B, Weitzenblum E. Predictive factors of hospitalization for acute exacerbation in a series of 64 patients with chronic obstructive pulmonary disease. Am J Respir Crit Care Med 1999; 159: $158-164$.

13. Kessler R, Faller M, Weitzenblum E, et al. "Natural history" of pulmonary hypertension in a series of 131 patients with chronic obstructive lung disease. Am J Respir Crit Care Med 2001; 164: 219-224.

14. Barberà JA, Riverola $\mathrm{A}$, Roca $\mathrm{J}$, et al. Pulmonary vascular abnormalities and ventilation-perfusion relationships in mild chronic obstructive pulmonary disease. Am J Respir Crit Care Med 1994; 149: 423-429.

15. Peinado VI, Barberà JA, Ramirez $\mathrm{J}$, et al. Endothelial dysfunction in pulmonary arteries of patients with mild COPD. Am J Physiol 1998; 274: L908-L913.

16. Wright JL, Petty T, Thurlbeck WM. Analysis of the structure of the muscular pulmonary arteries in patients with pulmonary hypertension and COPD: National Institutes of Health nocturnal oxygen therapy trial. Lung 1992; 170: $109-124$

17. Wilkinson M, Langhorne CA, Heath D, Barer GR, Howard P. A pathophysiological study of 10 cases of hypoxic cor pulmonale. $Q J$ Med 1988; 249: 65-85.

18. Magee F, Wright JL, Wiggs BR, Paré PD, Hogg JC. Pulmonary vascular structure and function in chronic obstructive pulmonary disease. Thorax 1988; 43: 183-189.

19. Wright JL, Lawson L, Paré PD, et al. The structure and function of the pulmonary vasculature in mild chronic obstructive pulmonary disease. Am Rev Respir Dis 1983; 128 : 702-707.

20. Hale KA, Niewoehner DE, Cosio MG. Morphologic 
changes in the muscular pulmonary arteries: Relationship to cigarette smoking, airway disease, and emphysema. Am Rev Respir Dis 1980; 122: 273-278.

21. Santos S, Peinado VI, Ramirez J, et al. Characterization of pulmonary vascular remodelling in smokers and patients with mild COPD. Eur Respir J 2002; 19: 632-638.

22. Dinh-Xuan AT, Higenbottam T, Clelland C, et al. Impairment of endothelium-dependent pulmonary-artery relaxation in chronic obstructive pulmonary disease. $N$ Engl $\mathrm{J}$ Med 1991; 324: 1539-1547.

23. Giaid A, Saleh D. Reduced expression of endothelial nitric oxide synthase in the lungs of patients with pulmonary hypertension. N Engl J Med 1995; 333: 214-221.

24. Barberà JA, Peinado VI, Santos S, Ramirez J, Roca J, Rodriguez-Roisin R. Reduced expression of endothelial nitric oxide synthase in pulmonary arteries of smokers. $\mathrm{Am}$ J Respir Crit Care Med 2001; 164: 709-713.

25. Tuder RM, Cool CD, Geraci MW, et al. Prostacyclin synthase expression is decreased in lungs from patients with severe pulmonary hypertension. Am J Respir Crit Care Med 1999; 159: 1925-1932.

26. Wedgwood S, Dettman RW, Black SM. ET-1 stimulates pulmonary arterial smooth muscle cell proliferation via induction of reactive oxygen species. Am J Physiol 2001; 281: L1058-L1067.

27. Giaid A, Yanagisawa M, Langblen D, et al. Expression of endothelin-1 in the lungs of patients with pulmonary hypertension. N Engl J Med 1993; 328: 1732-1739.

28. Tuder RM, Flook BE, Voelkel NF. Increased gene expression for VEGF and the VEGF receptors KDR/Flk and Flt in lungs exposed to acute or to chronic hypoxia. Modulation of gene expression by nitric oxide. J Clin Invest 1995; 95: 17981807.

29. Santos S, Peinado VI, Barberà JA, Ramirez J, Roca J, Gimferrer JM, Rodriguez-Roisin R. Enhanced expression of vascular endothelial growth factor (VEGF) in pulmonary muscular arteries of patients with COPD. Eur Respir J 2000; 16: Suppl. 31, 86s.

30. Heath D, Smith P, Rios DJ, Williams D, Harris P. Small pulmonary arteries in some natives of $\mathrm{La} \mathrm{Paz}$, Bolivia. Thorax 1981; 36: 599-604.

31. Meyrick B, Reid L. The effect of continued hypoxia on rat pulmonary arterial circulation. An ultrastructural study. Lab Invest 1978; 38: 188-200.

32. Stenmark K, Durmowicz AG, Dempsey EC. Modulation of vascular wall cell phenotype in pulmonary hypertension. In: Bishop JE, Reeves JT, Laurent GJ, eds. Pulmonary vascular remodelling. London, Portland Press, 1995; pp. 171-212.

33. Weitzenblum E, Schrijen F, Mohan-Kumar T, Colas dFV, Lockhart A. Variability of the pulmonary vascular response to acute hypoxia in chronic bronchitis. Chest 1988; 94: 772778.

34. Ashutosh K, Mead G, Dunsky M. Early effects of oxygen administration and prognosis in chronic obstructive pulmonary disease and cor pulmonale. Am Rev Respir Dis 1983; 127: $399-404$

35. Weitzenblum E, Sautegeau A, Ehrhart M, Mammosser M, Pelletier A. Long-term oxygen therapy can reverse the progression of pulmonary hypertension in patients with chronic obstructive pulmonary disease. Am Rev Respir Dis 1985; 131: 493-498.

36. Peinado VI, Barberà JA, Abate $\mathrm{P}$, et al. Inflammatory reaction in pulmonary muscular arteries of patients with mild chronic obstructive pulmonary disease. Am J Respir Crit Care Med 1999; 159: 1605-1611.

37. Wright JL, Churg A. Effect of long-term cigarette smoke exposure on pulmonary vascular structure and function in the guinea pig. Exp Lung Res 1991; 17: 997-1009.

38. Voelkel NF, Tuder RM. Cellular and molecular mechanisms in the pathogenesis of severe pulmonary hypertension. Eur Respir J 1995; 8: 2129-2138.

39. Su Y, Han W, Giraldo C, Li YD, Block ER. Effect of cigarette smoke extract on nitric oxide synthase in pulmonary artery endothelial cells. Am J Respir Cell Mol Biol 1998; 19: 819-825.

40. Yamato H, Churg A, Wright JL. Guinea pig pulmonary hypertension caused by cigarette smoke cannot be explained by capillary bed destruction. J Appl Physiol 1997; 82: 1644 1653.

41. Peinado VI, Santos S, Ramirez J, Roca J, Rodriguez-Roisin R, Barberà JA. Response to hypoxia of pulmonary arteries in COPD: an in vitro study. Eur Respir J 2002; 20: 332-338.

42. Naeije R. Should pulmonary hypertension be treated in chronic obstructive pulmonary disease?. In: Weir EK, Archer SL, Reeves JT, eds. The diagnosis and treatment of pulmonary hypertension. Mount Kisco, Futura Publishing, 1992; pp. 209 239.

43. Stevens D, Sharma K, Szidon P, Rich S, McLaughlin V, Kesten S. Severe pulmonary hypertension associated with COPD. Ann Transplant 2000; 5: 8-12.

44. Barberà JA. Chronic obstructive pulmonary disease. In: Roca J, Rodriguez-Roisin R, Wagner PD, eds. Pulmonary and peripheral gas exchange in health and disease. New York, Marcel Dekker, Inc., 2000; pp. 229-261.

45. Roca J, Wagner PD. Contribution of multiple inert gas elimination technique to pulmonary medicine. 1. Principles and information content of the multiple inert gas elimination technique. Thorax 1994; 49: 815-824.

46. Barberà JA, Roger N, Roca J, Rovira I, Higenbottam TW, Rodriguez-Roisin R. Worsening of pulmonary gas exchange with nitric oxide inhalation in chronic obstructive pulmonary disease. Lancet 1996; 347: 436-440.

47. Mélot C, Hallemans R, Naeije R, Mols P, Lejeune P. Deleterious effect of nifedipine on pulmonary gas exchange in chronic obstructive pulmonary disease. Am Rev Respir Dis 1984; 130: 612-616.

48. Ringsted CV, Eliasen K, Andersen JB, Heslet L, Qvist J. Ventilation-perfusion distributions and central hemodynamics in chronic obstructive pulmonary disease. Effects of terbutaline administration. Chest 1989; 96: 976-983.

49. Agustí AGN, Barberà JA, Roca J, Wagner PD, Guitart R, Rodriguez-Roisin R. Hypoxic pulmonary vasoconstriction and gas exchange during exercise in chronic obstructive pulmonary disease. Chest 1990; 97: 268-275.

50. Simonneau G, Escourrou P, Duroux P, Lockhart A. Inhibition of hypoxic pulmonary vasoconstriction by nifedipine. $N$ Engl J Med 1981; 304: 1582-1585.

51. MacNee W, Wathen CG, Hannan WJ, Flenley DC, Muir AL. Effects of pirbuterol and sodium nitroprusside on pulmonary haemodynamics in hypoxic cor pulmonale. BMJ (Clin Res Ed) 1983; 287: 1169-1172.

52. Lee-Chiong TL, Matthay RA. The heart in the stable COPD patient. In: Similowski T, Whitelaw WA, Derenne JP, eds. Clinical management of chronic obstructive pulmonary disease. New York, Marcel Dekker, Inc., 2002; pp. 475-532.

53. Brent BN, Berger HJ, Matthay RA, Mahler D, Pytlik L, Zaret BL. Physiologic correlates of right ventricular ejection fraction in chronic obstructive pulmonary disease: a combined radionuclide and hemodynamic study. Am J Cardiol 1982; 50: 255-262

54. Weitzenblum E, Chaouat A. Right ventricular function in COPD: can it be assessed reliably by the measurement of right ventricular ejection fraction? Chest 1998; 113: 567-569.

55. Crottogini AJ, Willshaw P. Calculating the end-systolic pressure-volume relation. Circulation 1991; 83: 1121-1123.

56. Biernacki W, Flenley DC, Muir AL, MacNee W. Pulmonary hypertension and right ventricular function in patients with COPD. Chest 1988; 94: 1169-1175.

57. MacNee W. Pathophysiology of cor pulmonale in chronic obstructive pulmonary disease. Part One. Am J Respir Crit Care Med 1994; 150: 833-852.

58. MacNee W. Pathophysiology of cor pulmonale in chronic obstructive pulmonary disease. Part Two. Am J Respir Crit Care Med 1994; 150: 1158-1168. 
59. Barberà JA, Roca $\mathrm{J}$, Ferrer $\mathrm{A}$, et al. Mechanisms of worsening gas exchange during acute exacerbations of chronic obstructive pulmonary disease. Eur Respir J 1997; 10: $1285-1291$.

60. Weitzenblum E, Apprill M, Oswald M, Chaouat A, Imbs JL. Pulmonary hemodynamics in patients with chronic obstructive pulmonary disease before and during an episode of peripheral edema. Chest 1994; 105: 1377-1382.

61. Campbell EJM, Short DS. The cause of oedema in "cor pulmonale". Lancet 1960; I: 1184-1186.

62. Baudouin SV. Oedema and cor pulmonale revisited. Thorax 1997; 52: 401-402.

63. MacNee W, Wathen CG, Flenley DC, Muir AD. The effects of controlled oxygen therapy on ventricular function in patients with stable and decompensated cor pulmonale. Am Rev Respir Dis 1988; 137: 1289-1295.

64. Palange P. Renal and hormonal abnormalities in chronic obstructive pulmonary disease (COPD). Thorax 1998; 53: 989-991.

65. Harris P, Segal N, Bishop JM. The relation between pressure and flow in the pulmonary circulation in normal subjects and in chronic bronchitis. Cardiovasc Res 1968; 2: 73-83.

66. Naeije R, Barberà JA. Pulmonary hypertension associated with COPD. Crit Care 2001; 5: 286-289.

67. Butler J, Schrijen F, Henriquez A, Polu JM, Albert RK. Cause of the raised wedge pressure on exercise in chronic obstructive pulmonary disease. Am Rev Respir Dis 1988; 138: 350-354.

68. Montes de Oca M, Rassulo J, Celli BR. Respiratory muscle and cardiopulmonary function during exercise in very severe COPD. Am J Respir Crit Care Med 1996; 154: 1284-1289.

69. Rubanyi GM, Romero JC, Vanhoutte PM. Flow-induced release of endothelium-derived relaxing factor. Am J Physiol 1986; 250: H1145-H1149.

70. Roger N, Barberà JA, Roca J, Rovira I, Gomez FP, Rodriguez-Roisin R. Nitric oxide inhalation during exercise in chronic obstructive pulmonary disease. Am J Respir Crit Care Med 1997; 156: 800-806.

71. Weitzenblum E. The pulmonary circulation and the heart in chronic lung disease. Monaldi Arch Chest Dis 1994; 49: 231234.

72. Chetty KG, Brown SE, Light RW. Identification of pulmonary hypertension in chronic obstructive pulmonary disease from routine chest radiographs. Am Rev Respir Dis 1982; 126: 338-341.

73. Wiedemann HP, Matthay RA. Heart Disease. A Textbook of Cardiovascular Medicine. 5th Edn. Philadelphia, WB Saunders Company, 1997.

74. Oswald-Mammosser M, Oswald T, Nyankiye E, Dickele MC, Grange D, Weitzenblum E. Non-invasive diagnosis of pulmonary hypertension in chronic obstructive pulmonary disease. Comparison of ECG, radiological measurements, echocardiography and myocardial scintigraphy. Eur J Respir Dis 1987; 71: 419-429.

75. Torbicki A, Skwarski K, Hawrylkiewicz I, Pasierski T, Miskiewicz Z, Zielinski J. Attempts at measuring pulmonary arterial pressure by means of Doppler echocardiography in patients with chronic lung disease. Eur Respir J 1989; 2: 856860.

76. Laaban JP, Diebold B, Zelinski R, Lafay M, Raffoul H, Rochemaure J. Noninvasive estimation of systolic pulmonary artery pressure using Doppler echocardiography in patients with chronic obstructive pulmonary disease. Chest 1989; 96: 1258-1262.

77. Naeije R, Torbicki A. More on the noninvasive diagnosis of pulmonary hypertension: Doppler echocardiography revisited. Eur Respir J 1995; 8: 1445-1449.

78. Takakura M, Harada T, Fukuno H, et al. Echocardiographic detection of occult cor pulmonale during exercise in patients with chronic obstructive pulmonary disease. Echocardiography 1999; 16: 127-134.

79. Matsuyama W, Ohkubo R, Michizono K, et al. Usefulness of transcutaneous Doppler jugular venous echo to predict pulmonary hypertension in COPD patients. Eur Respir $J$ 2001; 17: 1128-1131.

80. Kruger S, Haage P, Hoffmann R, et al. Diagnosis of pulmonary arterial hypertension and pulmonary embolism with magnetic resonance angiography. Chest 2001; 120: $1556-1561$.

81. Agustí AGN, Cotes J, Wagner PD. Responses to exercise in lung diseases. Eur Respir Mon 1997; 6: 32-50.

82. Minh VD, Lee HM, Dolan GF, Light RW, Bell J, Vasquez P. Hypoxemia during exercise in patients with chronic obstructive pulmonary disease. Am Rev Respir Dis 1979; 120: 787794.

83. Nery LE, Wasserman K, French W, Oren A, Davis JA Contrasting cardiovascular and respiratory responses to exercise in mitral valve and chronic obstructive pulmonary diseases. Chest 1983; 83: 446-453.

84. Miyamoto S, Nagaya N, Satoh T, et al. Clinical correlates and prognostic significance of six-minute walk test in patients with primary pulmonary hypertension. Comparison with cardiopulmonary exercise testing. Am J Respir Crit Care Med 2000; 161: 487-492.

85. Troosters $\mathrm{T}$, Vilaro J, Rabinovich R, et al. Physiological responses to the 6-min walk test in patients with chronic obstructive pulmonary disease. Eur Respir J 2002; 20: 564 569

86. Celli BR, Cote CG, Marín JM, Montes de Oca M, Casanova C, Méndez R. Combining 6MWD, FEV1, MRC dyspnea and BMI is better predictor of mortality than FEV1. Am J Respir Crit Care Med 2001; 163: A504.

87. Gerardi DA, Lovett L, Benoit-Connors ML, Reardon JZ, ZuWallack RL. Variables related to increased mortality following out-patient pulmonary rehabilitation. Eur Respir $J$ 1996; 9: 431-435.

88. Troosters T, Gosselink R, Decramer M. Short- and longterm effects of outpatient rehabilitation in patients with chronic obstructive pulmonary disease: a randomized trial Am J Med 2000; 109: 207-212.

89. Galie N, Manes A, Branzi A. The new clinical trials on pharmacological treatment in pulmonary arterial hypertension. Eur Respir J 2002; 20: 1037-1049.

90. Kharitonov SA, Barnes PJ. Exhaled Markers of Pulmonary Disease. Am J Respir Crit Care Med 2001; 163: 1693-1722.

91. Kharitonov SA, Cailes JB, Black CM, du Bois RM, Barnes PJ Decreased nitric oxide in the exhaled air of patients with systemic sclerosis with pulmonary hypertension. Thorax 1997; 52: 1051-1055.

92. Riley MS, Porszasz J, Miranda J, Engelen MP, Brundage B, Wasserman K. Exhaled nitric oxide during exercise in primary pulmonary hypertension and pulmonary fibrosis. Chest 1997; 111: 44-50.

93. Clini E, Cremona G, Campana M, et al. Production of endogenous nitric oxide in chronic obstructive pulmonary disease and patients with cor pulmonale. Correlates with echo-Doppler assessment. Am J Respir Crit Care Med 2000; 162: 446-450.

94. Yusen RD, Lefrak SS, Trulock EP. Evaluation and preoperative management of lung volume reduction surgery candidates. Clin Chest Med 1997; 18: 199-224.

95. Rich S, Kaufmann E, Levy PS. The effect of high doses of calcium-channel blockers on survival in primary pulmonary hypertension. N Engl J Med 1992; 327: 76-81.

96. Muramoto A, Caldwell J, Albert RK, Lakshminarayan S, Butler J. Nifedipine dilates the pulmonary vasculature without producing symptomatic systemic hypotension in upright resting and exercising patients with pulmonary hypertension secondary to chronic obstructive pulmonary disease. Am Rev Respir Dis 1985; 132: 963-966.

97. Naeije R, Melot C, Mols P, Hallemans R. Effects of vasodilators on hypoxic pulmonary vasoconstriction in normal man. Chest 1982; 82: 404410.

98. Bratel T, Hedenstierna G, Nyquist O, Ripe E. The use of a 
vasodilator, felodipine, as an adjuvant to long-term oxygen treatment in COLD patients. Eur Respir J 1990; 3: 46-54.

99. Andrivet P, Chabrier PE, Defouilloy C, Brun-Buisson C, Adnot $\mathrm{S}$. Intravenously administered atrial natriuretic factor in patients with COPD. Effects on ventilation-perfusion relationships and pulmonary hemodynamics. Chest 1994; 106: $118-124$

100. Adnot S, Kouyoumdjian C, Defouilloy C, et al. Hemodynamic and gas exchange responses to infusion of acetylcholine and inhalation of nitric oxide in patients with chronic obstructive lung disease and pulmonary hypertension. $\mathrm{Am}$ Rev Respir Dis 1993; 148: 310-316.

101. Sturani C, Bassein L, Schiavina M, Gunella G. Oral nifedipine in chronic cor pulmonale secondary to severe chronic obstructive pulmonary disease (COPD). Chest 1983; 84: $135-142$.

102. Agostoni P, Doria E, Galli C, Tamborini G, Guazzi MD. Nifedipine reduces pulmonary pressure and vascular tone during short- but not long-term treatment of pulmonary hypertension in patients with chronic obstructive pulmonary disease. Am Rev Respir Dis 1989; 139: 120-125.

103. Saadjian AY, Philip-Joet FF, Vestri R, Arnaud AG. Longterm treatment of chronic obstructive lung disease by Nifedipine: an 18-month haemodynamic study. Eur Respir $J$ 1988; 1: 716-720.

104. Pauwels RA, Buist AS, Calverley PMA, Jenkins CR, Hurd SS. Global strategy for the diagnosis, management, and prevention of chronic obstructive pulmonary disease. NHLBI/WHO Global Initiative for Chronic Obstructive Lung Disease (GOLD) Workshop Summary. Am J Respir Crit Care Med 2001; 163: 1256-1276.

105. Katayama Y, Higenbottam TW, Diaz de Atauri MJ, et al. Inhaled nitric oxide and arterial oxygen tension in patients with chronic obstructive pulmonary disease and severe pulmonary hypertension. Thorax 1997; 52: 120-124.

106. Frostell C, Blomqvist H, Hedenstierna G, Lundberg J, Zapol WM. Inhaled nitric oxide selectively reverses human hypoxic pulmonary vasoconstriction without causing systemic vasodilation. Anesthesiology 1993; 78: 427-435.

107. Katayama Y, Higenbottam TW, Cremona G, et al. Minimizing the inhaled dose of NO with breath-by-breath delivery of spikes of concentrated gas. Circulation 1998; 98: 2429-2432.

108. Siddons TE, Asif M, Higenbottam T. Does the method of delivery of inhaled nitric oxide influence oxygenation and VA/Q patterns in severe COPD? Eur Respir $J$ 2000; 16 : Suppl. 31, 267s.

109. Yoshida M, Taguchi O, Gabazza EC, et al. Combined inhalation of nitric oxide and oxygen in chronic obstructive pulmonary disease. Am J Respir Crit Care Med 1997; 155: 526-529.

110. Germann P, Ziesche R, Leitner C, et al. Addition of nitric oxide to oxygen improves cardiopulmonary function in patients with severe COPD. Chest 1998; 114: 29-35.

111. Ashutosh K, Phadke K, Jackson JF, Steele D. Use of nitric oxide inhalation in chronic obstructive pulmonary disease. Thorax 2000; 55: 109-113.

112. DeGaute JP, Domenighetti G, Naeije R, Vincent JL, Treyvaud D, Perret C. Oxygen delivery in acute exacerbation of chronic obstructive pulmonary disease. Effects of controlled oxygen therapy. Am Rev Respir Dis 1981; 124: 26-30.

113. Lejeune P, Mols P, Naeije R, Hallemans R, Melot C. Acute hemodynamic effects of controlled oxygen therapy in decompensated chronic obstructive pulmonary disease. Crit Care Med 1984; 12: 1032-1035.

114. Olvey SK, Reduto LA, Stevens PM, Deaton WJ, Miller RR. First pass radionuclide assessment of right and left ventricular ejection fraction in chronic pulmonary disease. Effect of oxygen upon exercise response. Chest 1980; 78: 4-9.
115. Report of the Medical Research Council Working Party. Long term domiciliary oxygen therapy in chronic hypoxic cor pulmonale complicating chronic bronchitis and emphysema. Lancet 1981; i: 681-685.

116. Nocturnal oxygen therapy trial group. Continuous or nocturnal oxygen therapy in hypoxemic chronic obstructive lung disease. A clinical trial. Ann Intern Med 1980; 93: 391398.

117. Brijker F, Heijdra YF, van den Elshout FJ, Folgering HT. Discontinuation of furosemide decreases $\mathrm{PaCO} 2$ in patients with COPD. Chest 2002; 121: 377-382.

118. Mathur PN, Powles P, Pugsley SO, McEwan MP, Campbell EJ. Effect of digoxin on right ventricular function in severe chronic airflow obstruction. A controlled clinical trial. Ann Intern Med 1981; 95: 283-288.

119. Polic S, Rumboldt Z, Dujic Z, Bagatin J, Deletis O, Rozga A. Role of digoxin in right ventricular failure due to chronic cor pulmonale. Int J Clin Pharmacol Res 1990; 10: 153-162.

120. Matthay RA, Berger HJ, Loke J, Gottschalk A, Zaret BL. Effects of aminophylline upon right and left ventricular performance in chronic obstructive pulmonary disease: noninvasive assessment by radionuclide angiocardiography. Am J Med 1978; 65: 903-910.

121. Mols P, Ham H, Naeije N, et al. How does salbutamol improve the ventricular performance in patients with chronic obstructive pulmonary disease? J Cardiovasc Pharmacol 1988; 12: 127-133.

122. Ballester E, Roca J, Ramis L, Wagner PD, Rodriguez-Roisin R. Pulmonary gas exchange in severe chronic asthma. Response to $100 \%$ oxygen and salbutamol. Am Rev Respir Dis 1990; 141: 558-562.

123. Chetty KG, Brown SE, Light RW. Improved exercise tolerance of the polycythemic lung patient following phlebotomy. Am J Med 1983; 74: 415-420.

124. Borst MM, Leschke M, Konig U, Worth H. Repetitive hemodilution in chronic obstructive pulmonary disease and pulmonary hypertension: effects on pulmonary hemodynamics, gas exchange, and exercise capacity. Respiration 1999; 66: 225-232.

125. Cooper JD, Patterson GA, Sundaresan RS, et al. Results of 150 consecutive bilateral lung volume reduction procedures in patients with severe emphysema. J Thorac Cardiovasc Surg 1996; 112: 1319-1329.

126. Weg IL, Rossoff L, McKeon K, Michael GL, Scharf SM. Development of pulmonary hypertension after lung volume reduction surgery. Am J Respir Crit Care Med 1999; 159: $552-556$

127. Sciurba FC, Rogers RM, Keenan RJ, et al. Brown ML, Landreneau RJ. Improvement in pulmonary function and elastic recoil after lung-reduction surgery for diffuse emphysema. N Engl J Med 1996; 334: 1095-1099.

128. Oswald-Mammosser M, Kessler R, Massard G, Wihlm JM, Weitzenblum E, Lonsdorfer J. Effect of lung volume reduction surgery on gas exchange and pulmonary hemodynamics at rest and during exercise. Am J Respir Crit Care Med 1998; 158: 1020-1025.

129. Wagner PD. Functional consequences of lung volume reduction surgery for COPD. Am J Respir Crit Care Med 1998; 158: 1017-1019.

130. Newman JH. Treatment of primary pulmonary hypertension - the next generation. N Engl J Med 2002; 346: 933-935.

131. Olschewski H, Ghofrani HA, Walmrath D, et al. Inhaled prostacyclin and iloprost in severe pulmonary hypertension secondary to lung fibrosis. Am J Respir Crit Care Med 1999; 160: 600-607.

132. Ghofrani HA, Wiedemann R, Rose F, et al. Sildenafil for treatment of lung fibrosis and pulmonary hypertension: a randomised controlled trial. Lancet 2002; 360: 895-900. 